\title{
A model for the simultaneous prediction of the flexural and shear deflections of statically
} determinate and indeterminate RC structures

\author{
Honeyeh Ramezansefat ${ }^{1}$, Joaquim Barros ${ }^{2}$, Mohammadali Rezazadeh ${ }^{3}$
}

\section{ABSTRACT:}

The deformability of the major part of reinforced concrete (RC) structures is the result of the flexural and shear deformations mainly caused by bending and shear diagonal cracking, respectively. However, the evaluation of the shear deformation contribution is relatively difficult due to the complexities involving the shear behavior of cracked RC elements. These complexities are even more complicated when structures are statically indeterminate, since the external and internal forces cannot be determined from direct application of the equilibrium equations. To address these issues, the current study aims to develop a novel simplified analytical model based on the flexibility (force) method to predict the deflections of statically indeterminate RC structures up to their failure, which can be in bending or in shear. This analytical model considers the influence of flexural cracks on the shear stiffness degradation of a RC structure after concrete cracking initiation, and has a format adjusted for design practice. The good predictive performance of the analytical model is demonstrated by simulating experimental tests with RC elements where shear deformation has different level of contribution for the total deflection registered in these tests.

Keyword: Flexural and shear deflection, analytical model, flexibility method, flexural and shear stiffness, determinate and indeterminate $\mathrm{RC}$ structure.

\footnotetext{
${ }^{1}$ ISISE, Post-doctoral Researcher of the Structural Division of the Dep. of Civil Engineering, University of Minho, 4800-058 Guimarães, Portugal, honeyrscivil@gmail.com

${ }^{2}$ ISISE, Full Professor of the Structural Division of the Dep. of Civil Engineering, University of Minho, 4800-058 Guimarães, Portugal, barros@ civil.uminho.pt

${ }^{3}$ ISISE, PhD of the Structural Division of the Dep. of Civil Engineering, University of Minho, 4800-058 Guimarães, Portugal, rzh.moh@gmail.com
} 


\section{Introduction}

23 Concerning the design and strengthening of reinforced concrete (RC) structures, an appropriate performance level

24 should be provided for the RC structures in serviceability limit state (SLS) conditions $[1,2,3]$. For this purpose, the 25 total deflection of a structure, resulting from flexural and shear deformations, should be limited to cover the 26 requirements of SLS due to deflection [1, 4]. In fact, after initiation of flexural cracks in a RC structure, in addition

27 of the reduction of flexural stiffness, the capability in transferring the shear forces of the structure is decreased, 28 which means that the shear stiffness is no longer in the elastic range after the generation of flexural cracks [5]. In 29 this regard, an analytical methodology, with a framework for being used by designers, considering the influence of 30 flexural cracking on the shear stiffness degradation before the occurrence of diagonal shear cracks, does not still exist according to the knowledge of the authors. In general, after the occurrence of flexural cracks, the reduction of

32 the element's stiffness consists of the flexural and shear stiffness degradations. In this context, the flexural stiffness 33 degradation is more noticeable than the corresponding shear stiffness degradation, since developing the flexural 34 cracks along the cross section causes more reduction on the flexural stiffness (determined using the relevant moment 35 of inertia of cross section (mm4)) than the shear stiffness (determined using the relevant cross sectional area $(\mathrm{mm} 2)$ )

36 [6]. This fact is prevalent up to the initiation of diagonal shear cracks, since after occurring these shear cracks, the

37 shear stiffness is reduced significantly. Therefore, neglecting the shear deformation when the diagonal shear cracks are propagating, leads to the significant underestimation of the total deflections of RC elements [7].

"Extensive research was carried out to analytically estimate the deflection of RC structures failing in bending, by taking into account the distribution of curvature along the length of the structure or by using the Technical Bending Theory (TB) that enables to determine the state of strain of cross-sections considering nonlinear material properties $[8,9,10,11] . "$ However, research efforts to analytically predict the contribution of shear deformation for total deflection of cracked RC structures are very limited, and consequently, developing a simplified model in this regard for designers 45 and engineers is still a task not yet comprehensively addressed [12,13]. In this context, Hansapinyo et al. [5] 46 proposed an empirical formulation analyzing the relevant experimental data to estimate the reduced effective shear 47 modulus of cross section after concrete cracking initiation, considering the axial longitudinal strain distribution along the cross section. Pan et al. [14] developed a theoretical calculation method for determining the effective shear 
stiffness of diagonally cracked RC beams based on the Truss Model (TM) considering the tension stiffening effect.

50 In other words, after diagonal cracking, this effective shear stiffness is defined to consider the shear stiffness

51 degradation due to the presence of more shear cracks as the shear force increases. In fact, by developing the diagonal

52 cracks, the shear transfer mechanism is correspondingly altered, and the fully diagonal cracked response is analyzed

53 using TM analogies in the proposed model. The value of the effective shear stiffness is between the elastic shear

54 stiffness and fully diagonal cracked shear stiffness..

55 Regarding the prediction of maximum capacity of RC structures failing in shear, there are two prominent models:

56 Truss Model (TM) and Modified Compression Field Theory (MCFT) [15, 16]. The TM is physically based on the

57 interpretation of the crack patterns formed during the loading process of a RC beam. However, this approach ignores

58 any contribution of the concrete in tension, resulting in conservative estimates of shear strength for RC concrete

59 members [17]. To take into account this resisting contribution of cracked concrete in tension, the MCFT was

60 developed to better predict the shear capacity of RC beams [18].

61 On the other hand, besides the available methods for the prediction of deflections of statically determinate

62 structures, developing the analytical methodologies, capable of predicting the deflections of statically indeterminate

63 structures, is rarely carried out by researchers due to the relevant complexities in this regard. In these statically

64 indeterminate structures, the number of redundant supports exceeds the number of static equilibrium equations

65 causing complexities to determine the external and internal forces of these types of structures by direct application

66 of the equilibrium equations. Furthermore, indeterminate structures are the most current in real practice since they

67 are more economic, safer and develop more ductile behavior than statically determinate structures [19].

68 Accordingly, the current study aims to develop a novel simplified analytical model using the force method (also

69 known as flexibility method) to predict the response of RC structures in terms of total deflections by considering the

70 contribution of flexural and shear deformations up to the failure of these structures. According to the proposed

71 model, the flexural deflections of a RC structure (due to bending moment) are estimated considering the tangential

72 flexural stiffness of the cross section obtained from the corresponding moment-curvature relationship of the section.

73 The shear deflections of a RC structure (due to shear force) is determined by considering the tangential shear

74 stiffness of the cross section during the loading process. For this purpose, the shear behavior of a RC structure is

75 assumed to be simulated by a three stage diagram representing the pre-cracking, post-cracking and post-diagonal 
cracking stages, delimited by the following points: concrete crack initiation; diagonal crack initiation; and ultimate

77 shear capacity. In this regard, the current study proposes a new strategy to evaluate the influence of flexural cracks 78 on the shear stiffness degradation of RC structure during the post-cracking stage. The applicability of the developed

79 analytical model is not limited to statically determinate RC elements, since the force method principles were used to

80

81

82

83 extend its use to statically indeterminate RC structures. The good predictive performance of the proposed model is appraised by predicting the force-deflection response registered in the experimental programs composed of determinate and indeterminate RC beams and slabs.

\section{Analytical model}

The following assumptions were adopted in the proposed analytical model:

a) Plane section orthogonal to the axis of the beam before deformation remains plane after deformation, and consequently the strain distribution along the depth of the cross section is directly proportional to the distance from the neutral axis;

b) There is no slip between steel reinforcement and surrounding concrete;

c) The maximum compressive strain in concrete is 0.003 .

For statically determinate structures, the external and internal forces can be entirely determined from the static equilibrium equations, while in the case of statically indeterminate structures; the number of redundant supports exceeds the number of static equilibrium equations, Displacement compatibility equations are established in order to derive a system of equations capable of determining the unknowns [19].

There are, mainly, two methods for the analysis of statically indeterminate structures namely, force method (also known as flexibility method) and displacement method (known as stiffness matrix method) [19]. In this study, an analytical model based on the flexibility method is proposed for the prediction of the material nonlinear behavior of determinate and indeterminate RC structures up to their collapse, considering the relevant mechanisms of flexural and shear stiffness degradation due to cracking formation and propagation. 
Fig. 1 schematically represents the loading and support configurations of the two span element adopted for assisting in the description of the present analytical study. In this regard, a displacement compatibility equation corresponding to the unknown reaction support should be established to determine the value of this reaction force. In case of aiming not only to determine the reaction, but also the displacements in the two loaded sections (in case $\Delta F_{1}$ and $\Delta F_{2}$ are known - force control test), or the force values in the loaded sections (in case $\Delta u_{1}$ and $\Delta u_{2}$ are known displacement control test), three compatibility equations must be established.

It is assumed that the principle of superposition can be applied to the behavior of the element in each small load increment $(\Delta F)$, even in the nonlinear phase response of the structure. Using this assumption, the structure is decomposed into a number of equilibrium configurations (each one is isostatic and determinate structure known as a released structure). In the present case, three displacement compatibility equations are established, two corresponding to the loaded sections, and the other to the intermediate support, in order to obtain the incremental

112 forces $\left(\Delta F_{1}\right.$ and $\Delta F_{2}$, assuming a displacement control test, where $\Delta u_{1}$ and $\Delta u_{2}$ are the imposed known displacements) and the corresponding incremental reaction ( $\Delta R$ ) (Fig. 2). For each equilibrium configuration, the 114 incremental forces $\left(\Delta F_{1}\right.$ and $\left.\Delta F_{2}\right)$ corresponding to the imposed incremental displacements $\left(\Delta u_{1}\right.$ and $\left.\Delta u_{2}\right)$ and 115 the relevant reaction $\Delta R$ are determined (Fig. 2). Regarding the determination of these forces using the flexibility method, the terms of the flexibility matrix, $f_{\Delta F_{1} \Delta F_{1}}, f_{\Delta F_{2} \Delta F_{1}}, f_{\Delta R \Delta F_{1}}, f_{\Delta F_{1} \Delta F_{2}}, f_{\Delta F_{2} \Delta F_{2}}, f_{\Delta R \Delta F_{2}}, f_{\Delta F_{1} \Delta R}, f_{\Delta F_{2} \Delta R}$,

117 and $f_{\Delta R \Delta R}$ (with a generic representation of $f_{i j}$ ) should be calculated [20]. Each term of flexibility matrix $\left(f_{i j}\right)$ is obtained by applying the principal of virtual work resulting:

$$
\begin{gathered}
f_{i j}=\int_{0}^{L} \frac{N_{i} N_{j}}{E A} d l+\int_{0}^{L} \frac{M_{i} M_{j}}{E I} d l+\int_{0}^{L} \frac{V_{i} V_{j}}{G A^{*}} d l+\int_{0}^{L} \frac{T_{i} T_{j}}{G J} d l \\
(a) \quad\left(a^{\prime}\right) \quad\left(a^{\prime \prime}\right)
\end{gathered}
$$
coordinate $j\left(F_{j}=1\right)$ on the released structure (see Fig. 2). By applying $F_{j}=1, N_{j}, M_{j}, V_{j}$, and $T_{j}$ are the 122 internal axial force, bending moment, shear force and torsional moment, respectively. Besides, by applying a unit 123 virtual load $F_{i}=1$ at coordinate $i$ on the released structure, following internal forces $N_{i}, M_{i}, V_{i}, T_{i}$ are 124 produced at any section. In Eq. (1) $E A, E I, G A^{*}, G J$ are the axial, flexural, shear and torsional stiffnesses, 
125 respectively. Also, $E$ is the modulus of elasticity, $I$ is the moment of inertia, $A$ and $A^{*}$ are the entire and 126 reduced, respctively, cross sectional area, $G$ is shear modulus and $J$ is the polar moment of inertia of the member.

127 In a 3D frame bar, two bending moments and two shear forces can develop in correspondence to the principal axis

128 of the cross section, but for the present version of the proposed model, a 2D bar is assumed, so the torsional term is 129 not considered, and only one bending component and one shear force is considered for the flexibility terms of 130 bending and shear. Furthermore the axial deformation is also neglected (term (a) in Eq. (1)), since the target type of 131 RC elements are those mainly submitted to bending and shear forces.

132 According to the principle of superposition effects, as represented in Fig. 2, the following three equations of 133 displacements compatibility can be established:

$$
\begin{aligned}
& \Delta u_{1}=f_{\Delta F_{1} \Delta F_{1}} \times \Delta F_{1}+f_{\Delta F_{1} \Delta F_{2}} \times \Delta F_{2}+f_{\Delta F_{1} \Delta R} \times \Delta R \\
& \Delta u_{2}=f_{\Delta F_{2} \Delta F_{1}} \times \Delta F_{1}+f_{\Delta F_{2} \Delta F_{2}} \times \Delta F_{2}+f_{\Delta F_{2} \Delta R} \times \Delta R \\
& 0=f_{\Delta R \Delta F_{1}} \times \Delta F_{1}+f_{\Delta R \Delta F_{2}} \times \Delta F_{2}+f_{\Delta R \Delta R} \times \Delta R
\end{aligned}
$$

and this equation can be rewritten in matrix format as:

$$
\left[\begin{array}{ccc}
f_{\Delta F_{1} \Delta F_{1}} & f_{\Delta F_{1} \Delta F_{2}} & f_{\Delta F_{1} \Delta R} \\
f_{\Delta F_{2} \Delta F_{1}} & f_{\Delta F_{2} \Delta F_{2}} & f_{\Delta F_{2} \Delta R} \\
f_{\Delta R \Delta F_{1}} & f_{\Delta R \Delta F_{2}} & f_{\Delta R \Delta R}
\end{array}\right]\left[\begin{array}{c}
\Delta F_{1} \\
\Delta F_{2} \\
\Delta R
\end{array}\right]=\left[\begin{array}{c}
\Delta u_{1} \\
\Delta u_{2} \\
0
\end{array}\right]
$$

or more concisely:

$$
\underline{f} \Delta \underline{F}=\underline{u}
$$

where $\underline{f}$ is the flexibility matrix; $\Delta \underline{F}$ is the vector of unknown applied forces $\left(\Delta F_{1}\right.$ and $\left.\Delta F_{2}\right)$ and reaction support

$141(\Delta R)$; and $\Delta \underline{u}$ is the vector of the imposed incremental displacements in the directions of $\Delta F_{1}, \Delta F_{2}$ and $\Delta R$ (the

142 displacement corresponding to $\Delta R$ is null). By solving Eq. (4) in terms of the vector of the unknown incremental 143 forces, $\Delta F$ is obtained:

$$
\left[\begin{array}{c}
\Delta F_{1} \\
\Delta F_{2} \\
\Delta R
\end{array}\right]=\left[\begin{array}{lll}
f_{\Delta F_{1} \Delta F_{1}} & f_{\Delta F_{1} \Delta F_{2}} & f_{\Delta F_{1} \Delta R} \\
f_{\Delta F_{2} \Delta F_{1}} & f_{\Delta F_{2} \Delta F_{2}} & f_{\Delta F_{2} \Delta R} \\
f_{\Delta R \Delta F_{1}} & f_{\Delta R \Delta F_{2}} & f_{\Delta R \Delta R}
\end{array}\right]^{-1}\left[\begin{array}{c}
\Delta u_{1} \\
\Delta u_{2} \\
0
\end{array}\right] \rightarrow \Delta \underline{F}=\underline{f}^{-1} \Delta \underline{u}
$$


145 The implementation of the proposed model to predict the total deflection (including the flexural and shear deformations) of statically determinate and indeterminate RC structures using the flexibility method is described in

147 the flowchart exposed in Fig. 3. In this algorithm, in the first block, the initial values of the accumulative variables 148 of the formulations are defined where theses initial values are represented by subscript "0", e.g., it is assumed that the initial value of the total force vector is null $\left(\underline{F}_{0}=0\right.$, block (1)). After the definition of initial values, a loop of displacement increments $\left(\Delta \underline{u}^{n}\right)$ is executed up to an assumed maximum deflection $\left(\underline{u}_{\max }\right)$. In each increment of the displacement, the bending moments and shear forces are updated in block (2). Then, each term of the flexibility matrix is determined in block (3) by evaluating the contribution of all the elements the structure is decomposed (nel), and considering the flexural and shear deformations according to Eq. (6) and to Eq. (7), respectively. In the next step, the incremental force vector is obtained in block (4) by applying Eq. (5). Then, the total force vector is this incremental loading process is ended.

\subsubsection{Flexural Part of the Flexibility Matrix}

The objective of this section is to describe the flexural part of the flexibility matrix ( $a^{\prime}$ in Eq. (1)). The diagrams of bending moments for the three equilibrium configurations of structure according to the superposition effects (see Fig. 2) are represented in Fig. 4. Each term of the flexibility matrix considering the internal work due to bending is obtained by:

$$
f_{i j}^{a^{\prime}}=\int_{0}^{L} \frac{M_{i} M_{j}}{E I} d l=\sum_{k=1}^{n e l}\left[\frac{M_{i, k} M_{j, k}}{(E I)_{k}} d l_{k}\right]
$$

where $L$ is the total length of structure; $E I$ is the cross section flexural stiffness of an element of length $d l ; M_{i}$ and $M_{j}$ are the bending moments in the released structure corresponding to the equilibrium configurations due to applying the unit load at coordinates $i\left(F_{i}=1\right)$ and $j\left(F_{j}=1\right)$, respectively. Due to the possible variation of the 167 structure in terms of geometry, bending moments or flexural stiffness, the structure is decomposed in a set of 
168 elements ( $n e l$ ) of length $d l_{k}$, where the bending moments $\left(M_{i, k}, M_{j, k}\right)$ and the flexural stiffness $(E I)_{k}$ is

169 calculated in the center of each element [19]. The bending moments for each $k$ element of the structure, $M_{i, k}$ and

$170 M_{j, k}$, are obtained in the step (2) of the algorithm represented in Fig. 3, where $M_{\Delta F_{1}}, M_{\Delta F_{2}}$ and $M_{\Delta R}$ are the

171 bending moments in the structure due to the loading configurations $\Delta F_{1}, \Delta F_{2}$ and $\Delta R$ represented in Fig. 4. In Eq.

172 (6) $(E I)_{k}$ is the tangent to the moment-curvature relationship of the cross section of the generic element $k$,

$173(M-\chi)_{k}$, for the updated applied moment $M_{k}^{n}$ at the loading step $n$, as represented in Fig. 5. In this context, in the

174 case of structures with different longitudinal reinforcement arrangement along the length, the structure length should

175 be discretized into the several elements considering an equal reinforcement arrangement along each element length

176 to determine the relevant $(E I)_{k}$ term.

177 In the current analytical study, the moment-curvature relationship $((M-\chi))$ of a cross section representative of a

178 generic element was determined using the sectional analysis software DOCROS (Design Of CROss Sections [21]).

179 It is assumed that a plane section remains plane after deformation and perfect bond exists between distinct materials.

"According to this sectional analysis software, a cross section is divided in layers. The thickness and the width of each layer depend on the cross section geometry and are defined by the user. Strain is considered the externally

182 applied load by selecting a layer to control the loading process. By applying the predefined strain on control layer

183 and assuming linear strain distribution along the depth of the section, curvature of the cross section is estimated

184 iteratively. Imposing incremental strain up to a definite limit, internal strain should arise in diverse layers,

185 consequently giving rise to internal forces that should balance the external loading conditions. Using constitutive

186 laws, the stresses corresponding to the strains in different layer are calculated. The depth of neutral axis is changing

187 iteratively until the force equilibrium is reached. Once the equilibrium is guaranteed, the bending moment is

188 determined".

189 DOCROS can analyze sections of irregular shape and size, subjected to constant axial load and variable curvature.

190 In addition of the moment-curvature relationship $(M-\chi)$ of element, DOCROS provide the neutral axis depth and

191 the tensile strain and stress in each layer of the cross section during the loading process. More detailed information 192 about the actual version of DOCROS can be found in [22]. 
194 This section aims to describe how the shear term of the flexibility matrix (see $a^{\prime \prime}$ in Eq. (1)) is evaluated. Fig. 6 indicates the shear force diagrams for the three equilibrium configurations of structure according to the

196 superposition effects represented in Fig. 2. Accordingly, considering the internal work due to shear, the shear 197 deformation contribution for the flexibility matrix is determined as follows:

$$
f_{i j}^{a "}=\int_{0}^{L} \frac{V_{i} V_{j}}{G A^{*}} d l=\sum_{k=1}^{n e l}\left[\frac{V_{i, k} V_{j, k}}{\left(G A^{*}\right)_{k}} d l_{k}\right]
$$

where $G A^{*}$ is the shear stiffness of an element with a length $d l ; V_{i}$ and $V_{j}$ are the shear forces in the released structure corresponding to the equilibrium configurations due to applying the unit load at coordinates $i\left(F_{i}=1\right)$ and $j$ $\left(F_{j}=1\right)$, respectively. When shear deformation is being considered, the discretization of a structure in elements should not only consider the characteristics that influence the flexure part of the flexibility matrix, but also the shear part, by considering the variation of cross section geometry, shear force or shear reinforcement arrangement along the structure length. Accordingly, the shear deformation is evaluated in the center of each of the nel elements the structure is decomposed, where the shear forces $\left(V_{i, k}, V_{j, k}\right)$ and the tangential shear stiffness $\left(G A^{*}\right)_{k}$ is calculated.

The shear forces for each $k$ element of the structure, $V_{i, k}$ and $V_{j, k}$, are obtained in the step (2) of the algorithm represented in Fig. 3, where $V_{\Delta F_{1}}, V_{\Delta F_{2}}$ and $V_{\Delta R}$ are the shear forces in the structure due to the loading configurations $\Delta F_{1}, \Delta F_{2}$ and $\Delta R$ represented in Fig. 6. the flexural and shear stiffness. In fact, the crack opening decreases the aggregate interlock shear mechanism, reducing the crack shear stress transfer capacity. On the other hand, the irregularities in the crack surface due to the

212 presence of aggregates promote the occurrence of crack opening during the crack shear sliding [23, 24], therefore 213 cracking process in a zone of shear forces and bending moments is governed by an interdependence of fracture mode I and fracture mode II model parameters. 
215 For taking into account the effect of cracks (composed of flexural and shear cracks) on the shear stiffness

216 degradation, the tangential shear stiffness $\left(G A^{*}\right)$ of the cross section of each element during the loading process is

217 determined assuming the corresponding shear force versus shear deformation $(V-\gamma)$ approach of the cross section

218 schematically represented in Fig. 7. According to this approach, the $V-\gamma$ response can be regarded as formed by

219 the pre-cracking, post-cracking, and post-diagonal cracking stages, delimited by the following points (Fig. 7):

220 concrete crack initiation (point (cr)); diagonal crack initiation (point (dcr)); and ultimate shear capacity (point (us)).

221 According to the experimental evidence, prior to flexural cracking (pre-cracking stage) the shear force applied on

222 the cross section is carried exclusively by the uncracked concrete, $V_{c z}$ (Fig. 8). Since the flexural cracking and the

223 initiation of the diagonal cracking, the external shear force is resisted by the uncracked concrete $\left(V_{c z}\right)$, the vertical

224 component $\left(V_{a y}\right)$ of the crack shear stress transfer capacity ( $V_{a}$, also known as aggregate interlock shear resisting

225 mechanism) and the dowel shear effect carried by the tensile longitudinal steel reinforcement ( $\left.V_{d}\right)$ (Fig. 8). After

226 diagonal cracking and before the yield initiation of stirrups (post-diagonal cracking stage), a portion of the applied

227 shear force is resisted by the web reinforcement $\left(V_{s}\right)$ (see Fig. 8). Following the yielding of steel stirrups, the

228 external shear force can only increase if the additional contribution of $V_{c z}, V_{d}$, and $V_{a y}$ is favorable in this respect,

229 since $V_{s}$ no longer increases (in case of assuming perfectly plastic behavior for the steel of this reinforcement). In

230 other words, after the steel stirrup yielding and before shear failure, as the inclined diagonal crack widens at an

231 increasing rate, the $V_{a y}$ decreases quickly, resulting in an increase of $V_{c z}$ and $V_{d}$. Eventually, shear failure occurs

232 due to either splitting (dowel) failure or compression zone failure due to combined shear and compression [25].

233 In next sections the shear stiffness for these stages is evaluated.

234 2.1.2.1. Precracking Stage

235 The pre-cracking stage corresponds to the linear elastic behavior of structure, where the flexural cracks still do not 236 appear. In other words, this pre-cracking stage is delimited by an instant when the tensile strain at the extreme 237 bottom fiber of concrete reaches its flexural tensile strength. During this stage, the shear stress along the depth of the cross section is linearly related to the shear strain $(\gamma)$ considering the shear modulus of concrete $\left(G_{e}\right)$ obtained by: 


$$
G_{e}=\frac{E_{c}}{2(1+v)}
$$

where $E_{c}$ and $v$ are the Young modulus and Poisson coefficient of concrete, respectively. Accordingly, the cross sectional shear stiffness $\left(G A^{*}\right)$ can be accurately estimated by multiplying the shear modulus of concrete $\left(G_{e}\right)$ with shear resistance surface $\left(A^{*}\right)$ obtained from:

$$
A^{*}=\frac{b \cdot d}{f_{s}}
$$

where $b$ and $d$ are the width and height of cross section, and $f_{s}$ is the shear correction factor according to the Timoshenko theory. In fact, this shear correction factor is defined to accurately consider the shear deformation effects caused by non-uniform distribution of the shear stresses over the cross-section of the beam [6, 26]. According to the Timoshenko theory, the shear correction factor depends on Poisson's ratio as follows:

$$
f_{s}=\frac{1}{k} \rightarrow k=\frac{5+5 v}{6+5 v}
$$

In rectangular cross section elements the most used factor is given as $f_{s}=6 / 5$, which is obtained by assuming a parabolic shear stress distribution over the cross-section $[6,26]$

\subsubsection{Post-cracking Stage}

By increasing the load over the concrete crack initiation and subsequent generation of flexural cracks in shear span, this concrete cracking stage is followed by initiating the shear diagonal cracking in the shear span of structure, where the load carrying capacity of RC structure corresponding to this shear diagonal cracking stage $\left(V_{d c r}\right)$ is obtained according to the recommendation of ACI-318 [1,27] design guideline considering the shear strength of the cross section provided by concrete as follows:

$$
V_{d c r}=V_{c}=0.17 \sqrt{f_{c}} b_{w} d_{s}
$$

where $f_{c}$ is the compressive strength of concrete; $b_{w}$ and $d_{s}$ are the web thickness of cross section and internal arm of longitudinal tensile steel bars, respectively. 
During this stage (after the concrete crack initiation up to the shear diagonal crack initiation which is known as post-

262

263

264

265

266

267

In order to determine the shear retention factor $(\beta)$, considering the aggregate interlock and longitudinal

274 reinforcement effects, the following equations were proposed by [30] based on the experimental results conducted

275 by $[31,32,33]$ :

277 where

281 and

$$
C_{1}=7+5 \frac{\rho_{e q, e f}^{e}-0.005}{0.015}
$$

$$
\beta=-\frac{\ln \left(\frac{\varepsilon_{c t}}{C_{1}}\right)}{C_{2}}
$$

$$
C_{2}=10-2.5 \frac{\rho_{e q, e f}^{e}-0.005}{0.015}
$$

where $\rho_{e q, e f}^{e}$ is the effective longitudinal reinforcement ratio according to the Eurocode recommendations [34]. Since $\beta$ should be less than the unit value, it should be respected the following condition:

$$
\varepsilon_{c t}(\% \mathrm{o})>C_{1} \exp \left(-C_{2}\right)
$$



tensile strain of concrete $\left(\varepsilon_{c t}\right)$ and the ultimate concrete tensile strain $\left(\varepsilon_{c t u}\right)$, as follows:

$$
\beta=\left(1-\frac{\varepsilon_{c t}}{\varepsilon_{c t u}}\right)^{p}
$$

In this equation, $P$ is a parameter that determines the shape of reduction of concrete shear modulus by increasing the concrete tensile strain, and can adopt the value of 1,2, or 3 [35]. tension zone is divided in layers of relatively small thickness (no more than $10 \%$ of the cross section depth). Hence, assuming a linear proportionality of strain distribution along the depth of the cross section with regard to the neutral axis level, the mean strain in each layer is taken as a representative concrete tensile strain to calculate the corresponding value of the shear modulus retention factor $\left(\beta_{a}\right)$ of the layer. Accordingly, during the post-cracking stage, the sectional shear stiffness ( $\left.G A^{*}\right)$ is obtained using Eq. (14) considering the corresponding shear stiffness of compression zone $\left(G A_{c c}^{*}\right)$ and tension zone $\left(G A_{c t}^{*}\right)$ of the cross section (represented in Fig. 9):

$$
G A^{*}=G A_{c c}^{*}+G A_{c t}^{*}=\frac{G_{e} \cdot b \cdot c}{f_{s}}+\frac{G_{e} \cdot b}{f_{s}} \sum_{a=1}^{m} \beta_{a} \cdot h_{a}
$$
analysis using DOCROS software. $h_{a}$ is the thickness of each layer determining via dividing the tension zone depth (which is obtain by deducting neutral axis depth from the total element depth) by chosen number of layers $(m)$ in concrete tension zone.

On the other hand, adopting the neutral axis depth of cross section during the loading process for determining the shear stiffness of compression zone $\left(G A_{c c}^{*}\right)$ and tension zone $\left(G A_{c t}^{*}\right.$, in terms of calculating $\beta$ parameter), highlights the potential of the proposed analytical model to take into account the influence of the flexural stiffness degradation during the post-cracking stage on the shear stiffness $\left(G A^{*}\right)$ of the cross section. In other words, by increasing the applied load during this stage, the decrease of the neutral axis depth of cross section results in a reduction of sectional shear stiffness ( $G A^{*}$ ) considering Eq. (14). 


\subsubsection{Post-diagonal cracking stage}

309 The post-diagonal cracking corresponds to the stage where the internal shear force of cross section exceeds the 310 corresponding diagonal shear strength (obtained by Eq. (11)). On the other hand, in the present section, the ultimate

311 load carrying capacity of the cross section is controlled by adopting the shear failure [2]. Concerning the shear 312 failure, the ultimate load carrying capacity of the cross section is determined using a simplified analytical model 313 according to the modified compression field theory (MCFT) proposed by Bentz et al. [17]. According to this model, 314 the shear strength of a section is a function of two parameters of $\beta_{s}$ and $\theta_{s}$. These two parameters are a factor for 315 tensile stresses in the cracked concrete $\left(\beta_{s}\right)$ and the inclination of the diagonal compressive stresses in the web of cross section $\left(\theta_{s}\right)$. Moreover, both of these parameters are functions of longitudinal strain $\varepsilon_{x}$ and the equivalent

317 crack spacing $s_{x e}$. Accordingly, the shear strength of the web of cross section $(v)$ is determined using this 318 simplified MCFT procedure as follows:

$$
v=v_{c}+v_{s}=\beta_{s} \sqrt{f_{c}}+\rho_{w} f_{y} \cot \theta_{s}
$$

320 Where

$$
\varepsilon_{x}=\frac{f_{s x}}{E_{s}}=\frac{v \cot \theta-v_{c} / \cot \theta}{E_{s} \rho_{x}}
$$

In Eq. (15a) $v_{c}$ and $v_{s}$ are the concrete and steel stirrups shear contributions, respectively, and $\rho_{w}$ is the ratio of stirrup area $\left(A_{v}\right)$ to the web area $\left(b_{w} . s\right.$, where $s$ is the distance between steel stirrups). In Eqs. (15b) and (15c), $\varepsilon_{x}$ is longitudinal strain of the web (tensile positive, compressive negative) obtained by iterative procedure. In this regard, the calculations start by assuming an initial value of $1.0 \times 10^{-3}$ for $\varepsilon_{x}$ [17]. For solving Eqs. (15b) and (15c), 
329 it is needed to obtain $s_{x e}$ by Eq. $(15 \mathrm{~d})$, where the term $a_{g}$ is equal to the maximum coarse aggregate size and $s_{x}$ is

330 the vertical distance between longitudinal bars in the x-direction (element axis) considered as the greater of $0.9 d s$

331 or $0.72 h$ (Fig. 10a). By using these values $\left(s_{x e}, \varepsilon_{x}\right)$ for solving Eqs. (15b) and (15c), $\beta_{s}$ and $\theta_{s}$ are determined.

332 By substituting these values $\left(\beta_{s}\right.$ and $\left.\theta_{s}\right)$ in Eq. (15a), the shear strength of the web of cross section ( $v$ ) is

333 determined. By applying $v$ in Eq. (15e), the new value of $\varepsilon_{x}$ is obtained. If the difference between the assumed

334 value and this new obtained value of $\varepsilon_{x}$ is higher than an assumed tolerance $(0.01 \%)$, a new estimation of $\varepsilon_{x}$

335 requires to be made and the calculations should be repeated, otherwise, convergence is reached and the shear strength of the cross section $(v)$ is determined by using this value of longitudinal strain.

337 To simulate the shear stiffness degradation of cross section during the post-diagonal cracking stage, two boundary states corresponding to the diagonal shear crack initiation and fully developed diagonal shear crack are considered (Fig. 10b). The proposed mean value of shear strain $\left(\gamma_{m}\right)$ between these two boundaries is defined according to the shear strains corresponding to the initiation of diagonal shear cracking $\left(\gamma_{d c r}\right)$ and full development of diagonal

341 shear cracking $\left(\gamma_{u s}\right)$ (Fig 10b). In this context, $\gamma_{d c r}$ is determined dividing the applied shear load ( $V$ ) in the

342 element when is equal to the $V_{d c r}$ (determined from Eq. (11)) by corresponding shear stiffness of cross section,

$343\left(G A^{*}\right)_{d c r}$, at the diagonal shear crack initiation stage. To determine this shear stiffness $\left(G A^{*}\right)_{d c r}$ using Eq. (14), the

344 neutral axis depth in this equation is calculated considering the corresponding moment $\left(M_{d c r}\right)$ at the diagonal shear 345 crack initiation stage. In fact, using Eq. (14) for determining the $\gamma_{d c r}$, the degrading effects of flexural cracking on 346 the shear stiffness in the post-cracking stage are taken into account during the post-diagonal cracking stage:

$$
\gamma_{d c r}=\frac{V_{d c r}}{\left(G A^{*}\right)_{d c r}}
$$

Concerning the determination of the shear strain of fully diagonal shear cracked $\left(\gamma_{u s}\right)$, this shear strain is obtained based on recommendation of CEB Manual [36] using truss model analogies: 


$$
\gamma_{u s}=\frac{V}{0.9 d_{s} b_{w}}\left(\frac{1}{\rho_{w} E_{s}(\cot g \alpha+1)^{2} \sin ^{4} \alpha}+\frac{4}{E_{c}(\cot g \alpha+1)^{2}}\right)
$$

where

$$
\rho_{w}=\frac{A_{v}}{s b_{w} \sin \alpha}
$$
as:

$$
\gamma_{u s}=\frac{V}{0.9 d_{s} b_{w}}\left(\frac{1}{\rho_{w} E_{s}}+\frac{4}{E_{c}}\right)
$$
CEB manual recommendations [36]:

$$
\gamma_{m}=(1-\zeta) \gamma_{d c r}+\zeta \gamma_{u s}
$$

where $\zeta$ is a function of the applied shear force $(V)$, and is obtained by:

$$
\zeta=0 \quad \text { for } \quad V \leq V_{d c r}
$$

$$
\begin{gathered}
\zeta=1-\left(\frac{4 V_{d c r}-V}{3 V_{d c r}}\right)^{2} \quad \text { for } \quad V_{d c r}<V<4 V_{d c r} \\
\zeta=1 \quad \text { for } \quad V \geq 4 V_{d c r}
\end{gathered}
$$
effective shear modulus ( $G_{\text {eff }}$ ) of the cross section, which is obtained by:

$$
G=G_{e f f}=\frac{V}{\gamma_{m} A^{*}}
$$


371 The objective of the present section is to assess the performance of the described analytical model to predict the 372 response of indeterminate and determinate RC structures. Regarding the assessment of the performance of the 373 proposed analytical model for predicting the response of indeterminate RC structures, the flexural terms of the 374 proposed analytical model were applied on the prediction of the flexural behavior of the statically indeterminate unstrengthened and flexurally strengthened RC slabs using fiber reinforced polymer (FRP) applied according to the

376 near surface mounted (NSM) technique [20]. These indeterminate RC slabs had two spans with one degree of 377 indeterminacy (see Fig.11). In fact, the shear term of the analytical model was neglected to predict the responses of these indeterminate slabs, since the contribution of the shear term of the model for the response of these types of 379 structures is marginal. In Fig.11 the force-deflection responses obtained analytically using the flexural term of the 380 described model and registered experimentally are compared for the unstrengthened and strengthened indeterminate

381 RC slabs. This figure evidences that the developed model is capable of predicting the response of these types of 382 structures with good accuracy up to a very high deflection level. More detailed information about this assessment of 383 the predictive performance of the analytical model concerning the response of indeterminate RC structures can be found in [20].

In the following, the proposed analytical model is applied on the prediction of the responses of determinate RC beams (with rectangular, square, T-cross sectional area, I-cross sectional area and large depth beam), where the influence of the shear deformation on the total deflection is significant and, therefore, should be not negligible.

The flexural and shear deformations of two rectangular RC beams with web shear reinforcement obtained in the experimental tests carried out by Hansapinyo et al. [5], are analytically predicted using the proposed model. The experimental mid-span deflections of these RC beams were reported separately in terms of the flexural, shear, and total deflections. In this reference [5] the authors describe the procedure adopted to determine the deflection part due to shear deformation by considering the adopted monitoring system. The data defining the geometry, reinforcement details, and main material properties of these beams is included in Table 1. The beams were simply supported, and 
failed by yielding of the longitudinal tensile steel bars before shear diagonal failure, while in the other beam (designated by SP2), the shear diagonal failure was occurred before yielding of the longitudinal tensile steel bars.

\subsubsection{Assessment of analytical model according to ACI and CEB recommendations}

401 According to the proposed model, the shear diagonal strength is determined based on the recommendations of ACI402318 design guideline [1] (Eq.(11)), since the shear diagonal strength recommended by this design guideline provides 403 a more accurate response of RC beam compared to the corresponding response obtained using the recommendations 404 of CEB manual [36] in this regard. These recommendations of CEB manual are as follows:

$$
V_{D c r}=\tau_{r} \cdot k\left(1+50 . \rho_{l}\right) b_{w} \cdot d_{s}
$$

406 where

$$
k=1.6-d_{s} \geq 1 \quad \text { (here } d_{s} \text { is in meter) }
$$

$$
\rho_{l}=\frac{A_{s l}}{b_{w} \cdot d_{s}} \leq 0.02
$$
longitudinal tensile steel reinforcement.

411 In this regard, Fig. 12 compares the load versus total mid-span deflection relationship registered experimentally and 412 obtained analytically using ACI-318 design guideline and CEB manual recommendations, for the SP1 beam. 413 Analyzing this figure, it is observed that the response of the SP1 beam in terms of load versus total mid-span

414 deflection relationship was analytically predicted using the recommendations of ACI-318 for the shear diagonal 415 strength with higher accuracy compared to the corresponding response obtained according to the recommendations of CEB manual. 
419 The good predictive performance of the proposed analytical model regarding the prediction of the flexural and shear 420 deformations of the SP1 and SP2 beams is demonstrated in Figs. 13 and 14, respectively. Furthermore, the 421 maximum shear capacity of these analyzed beams obtained by simplified MCFT procedure was accurately 422 accommodated to the corresponding experimental capacity. However, this maximum shear capacity of the SP1 beam 423 (see Fig. 13a) was analytically predicted immediately after the yielding of longitudinal steel bars, which was the 424 case observed experimentally.

425 To highlight the influence of shear deformation on the prediction of total deflection of RC structure, Fig. 15 426 compares the analytical total deflections of the SP1 and SP2 beams (obtained by considering the contribution of 427 flexural and shear deformations) with the corresponding flexural deflections obtained using only the flexural terms of the analytical model and the proposed formulation in the ACI-318 to estimate the flexural response of RC

429 structure [1]. According to the recommendation of ACI-318, the deflections of a cracked RC structure can be 430 estimated using the elasticity modulus for concrete $\left(E_{c}\right)$ and effective moment of inertia $\left(I_{e}\right)$ proposed by Branson 431 as follows [1, 37]:

$$
I_{e}=\left(\frac{M_{c r}}{M_{a}}\right)^{3} I_{g}+\left[1-\left(\frac{M_{c r}}{M_{a}}\right)^{3}\right] I_{c r} \leq I_{g}
$$

where $M_{c r}$ and $M_{a}$ are the cracking and maximum applied bending moments in the element, respectively; $I_{g}$ and $I_{c r}$ are, respectively, the moment of inertia of the section in the uncracked and fully cracked conditions. $I_{c r}$ is obtained by transforming the cross sectional area of longitudinal steel reinforcement to the corresponding equivalent concrete area, and the moment of inertia of fully cracked section is determined considering the corresponding neutral axis depth of the section. Hence, Fig. 15 confirms the importance of considering the shear deformations to more accurate prediction of total deflections of RC structure. 
simulating the experimental tests conducted by Barros et al. [38]. The data defining the geometry and reinforcement details, as well as the main material properties of this experimental program is included in Table 2. The beams were

445 simply supported, and were monotonically tested under four-point loading. Moreover, the RC beam with rectangular 446 cross section (SP3) failed by yielding of the longitudinal tensile steel reinforcement immediately followed by the

447 diagonal shear failure, while the shear failure was occurred in the RC beam with square cross sectional (SP4) before 448 steel yielding. The relationship between the applied loads versus the total deflections of mid-span cross section 449 obtained analytically and experimentally is depicted in Fig. 16, where is demonstrated the good predictive performance of the analytical model regarding the prediction of the total deflections of RC beams with rectangular and square cross sectional area. Moreover, the adopted simplified MCFT procedure for estimating the maximum

452 shear capacity of cross section predicted with good accuracy the maximum load carrying capacity of the analyzed beams. However, the yielding of the longitudinal tensile steel reinforcement was occurred at a lower load carrying capacity than the corresponding one registered experimentally for the SP3 and SP4 beams, which may be attributed to the reported material properties for the analyzed beams.

To appraise the performance of the proposed analytical model, it is applied on the prediction of the response of two T-cross section RC beams tested by Panda et al. [39]. The characteristics of these beams in terms of the geometry and reinforcement details are represented in Table 3. Moreover, this table includes the average values of the main material properties for the analyzed beams. These two simply supported beams were monotonically tested under four-point loading configuration. The maximum capacity of both T-cross section RC beams (designated by SP5 and SP6) was controlled by the occurrence of shear failure. Fig. 17 compares the load versus mid-span total deflection

464 relationship obtained analytically and registered experimentally for the RC beams. A good predictive performance of the proposed analytical model is achieved for the tested beams. However, the simplified MCFT has 466 underestimated the maximum shear capacity of the beams. 
To assess the predictive performance of the proposed model, one simply supported I-cross section RC beam subjected to two symmetrical loads, tested by Debernardi et al. [40], was simulated. The characteristics of this beam in terms of the geometry and reinforcement details are provided in the Table 4 . This simply supported beam was

471 monotonically tested under four-point loading configuration. Fig. 18 demonstrates that the proposed analytical

472 model is capable of predicting with high accuracy the deflection behavior of this type of structures. Likewise, as 473 shown in Fig.18, the maximum shear capacity of the cross section obtained by MCFT approach matches very well 474 the value registered experimentally."

477 For evaluating the capability of the proposed model to predict the behavior of large depth beam, it is implemented on the simulation of a simple supported beam with relatively large depth subjected to uniformly distributed loads 479 tested by Perkins et al.[41]. The data defining the geometry and reinforcement details, as well as the main material properties of this experimental program is included in Table 5. The comparisons between the results obtained analytically and registered experimentally for the analyzed large depth RC beam are shown in Fig. 19. The obtained 482 results reveal that, for the case of beam with relatively large depth, using the ACI-318 recommendation for the shear diagonal strength, Eq.(11), provides an inaccurate prediction of the beam response since in this equation, the coefficient of 0.17 was empirically obtained by taking into account the results from experimental tests on the regular beams. Thus, the ACI-318 proposed equation is not applicable for the case of beam with relatively large depth, like the beams used in bridge structure, since it is calibrated for the regular civil engineering structural beams.

487 On the other hand, in the FIB Model Code 2010 (MC-2010) [42], the shear strength of the cross section provided by concrete is obtained from the following equation:

$$
V_{d c r}=k_{v} \sqrt{f_{c k}} b_{w} z
$$

$$
k_{v}=\frac{180}{1000+1.25 \mathrm{z}}
$$


where $\mathrm{z}$ is the effective shear depth that can be assumed equal to $0.9 d(\mathrm{~mm}), f_{c k}$ is characteristic value of concrete compressive strength and $b_{w}$ is the width of the beam's web.

Using the above-mentioned MC-2010 recommendation for calculating the shear diagonal strength in the proposed model, the relationship between the applied loads versus the mid-span total deflections of the analyzed beam with relatively large depth is analytically predicted and represented in Fig.19. In this figure, the comparisons of the experimental data with the analytical response, according to the MC-2010 recommendation for the shear diagonal strength, show a better predictive performance of the proposed analytical model when compared to the corresponding analytical response according to the ACI-318 recommendation. This fact can be attributed to the size 500 effect consideration of MC-2010 recommendation for the shear diagonal strength. However, for the case of regular 501 beams, the shear strength of the cross section obtained by using this formulation is almost similar to the shear strength provided by the ACI-318 recommendation. On the other hand, Fig.19 evidences that the prediction of maximum shear capacity of the beams with relatively large depth using the simplified MCFT was underestimate."

\section{Conclusions}

The current study aimed to develop a novel analytical model with a design framework, based on the flexibility (force) method, to simultaneously or separately predict the flexural and shear deformations of RC structures due to the relevant nonlinearities occurred in the constituent materials up to the collapse (in flexure or shear) of these structures, such as flexural and shear cracks in concrete and plastic strains. The applicability of the developed analytical model is not limited to statically determinate RC elements, since the force method principles were used to extend its use to statically indeterminate RC structures.

512 In this model, the ultimate load carrying capacity of the cross section is controlled by considering the possibility of occurring a flexural failure (yielding of the steel bars in tension) or shear diagonal failure (according to modified

514 compression field theory (MCFT)). The flexural deflections of a structure are determined using the tangential 515 flexural stiffness of the representative cross sections of this structure, obtained from the corresponding momentcurvature relationship. For evaluating the shear deflections of a structure, the tangential shear stiffness of the

517 representative cross sections of this structure during the loading process was obtained by assuming the shear 
518 stiffness evolution can have a pre-cracking, post-cracking, and post-diagonal cracking stages delimited by the 519 concrete crack initiation; diagonal crack initiation; and ultimate shear capacity, respectively. Since after the 520 generation of flexural cracks, the shear stiffness is no longer in the elastic range, another objective of the current

521 model was to propose a methodology to take into account the influence of the extension of flexural cracks during the 522 post-cracking stage on the shear stiffness degradation.

523 The results of experimental programs composed of RC beams with rectangular, square, - T-cross sectional area, I524 cross sectional area and large depth beam in terms of load versus total, flexural, and shear deflections, were 525 compared with the ones obtained by the proposed analytical model, and a good predictive performance was 526 evidenced. Moreover, the good predictive performance of the model regarding the response of statically 527 indeterminate structures was confirmed by simulating RC slabs with one degree of indeterminacy.

\section{Acknowledgements}

530 The first and second authors acknowledge the support of Marie Curie Initial Training Network under the project 531 "ENDURE" with reference number 607851, funded by the EU programme: FP7-people. The study reported in the 532 paper is part of the ongoing research activities in the scope of project ENDURE. The third author acknowledges the grant provided by TecMinho. 
$a_{g}$ : maximum coarse aggregate size, $(\mathrm{mm})$;

$b_{w}$ : web thickness of cross section, (mm);

$c$ : neutral axis depth, (mm);

$d_{s}$ : web thickness of cross section, (mm);

$E$ : modulus of elasticity, (MPa);

$f_{c}$ : compressive strength of concrete, (MPa);

$f_{i j}$ : components of flexibility matrix;

$f_{s}:$ shear correction factor;

$G$ : shear modulus, (MPa);

$h:$ total depth of section, (mm);

$h_{f}$ : thickness of each layer in tension zone, $(\mathrm{mm})$;

$I$ : moment of inertia, $\left(\mathrm{mm}^{4}\right)$;

$J$ : polar moment of inertia, $\left(\mathrm{mm}^{4}\right)$;

$L:$ length of the structure, $(\mathrm{mm})$;

$M$ : internal bending moment, (N.mm);

$N$ : internal axial force, $(\mathrm{N})$;

$T:$ internal torsional moment, (N.mm);

$V$ : internal shear force, $(\mathrm{N})$;

$V_{s}$ : the shear carried by transverse reinforcement, $(\mathrm{N})$; $\beta$ : shear modulus retention factor;

$\beta_{s}$ : factor for tensile stresses in the cracked concrete;

$d l_{k}$ : length of element $\mathrm{k},(\mathrm{mm})$;

$\Delta F$ : load increment, $(\mathrm{N})$;

$\Delta u$ : incremental displacements, (mm);

$\varepsilon_{c t u}:$ ultimate concrete tensile strain;

$\varepsilon_{c t}$ : axial tensile strain of concrete;

$\varepsilon_{x}$ : longitudinal strain;

nel : number of element;

$\rho_{w}$ : ratio of stirrup area to the web area;

$\rho_{x}$ ratio of longitudinal reinforcement

$s_{x e}$ : equivalent crack spacing, $(\mathrm{mm})$;

$\theta_{s}$ : inclination of the web diagonal compressive stresses;

$v$ : Poisson ratio;

$\chi:$ Curvature;

$\gamma:$ shear strain; 


\section{References}

540 [1] ACI Committee 318. Building code requirements for structural concrete and commentary, American Concrete 541 Institute, Reported by ACI Committee 318; 2002.

542 [2] ACI-440.2R. Guide for the design and construction of externally bonded FRP systems for strengthening concrete 543 structures, American Concrete Institute (ACI) Committee 440; 2008.

544 [3] Rezazadeh M, Ramezansefat H, Barros J. NSM CFRP prestressing techniques with strengthening potential for

545

546

547

548

549

550

551

552

553

554

555

556

557

558

559

560

561

562

563

564

565

566

567

568

569

570

571

572

573

574

575

576

577

578

579

580

581

582

583

584 simultaneously enhancing load capacity and ductility performance. Journal of Composites for Construction 2016; 10:04016029.[4] Rezazadeh M, Costa I, Barros J. Influence of prestress level on NSM CFRP laminates for the flexural strengthening of RC beams. Composite Structures 2014; 116: 489-500.

[5] Hansapinyo C, Pimanmas A, Maekawa K, Chaisomphob T. Proposed model of shear deformation of reinforced concrete beam after diagonal cracking. Journal of Materials, Concrete Structures and Pavements, JSCE 2003; 725(58):305-19.

[6] Gere J, Timoshenko S. Mechanics of materials. London: Chapman and Hall; 1991.

[7] Belletti B, Damoni C, Hendriks MA, de Boer A. Analytical and numerical evaluation of the design shear resistance of reinforced concrete slabs. Structural Concrete 2014; 1;15(3):317-30.

[8] Rezazadeh M, Barros J., Costa I. Analytical approach for the flexural analysis of RC beams strengthened with prestressed CFRP. Composites Part B: Engineering 2015; 73:16-34.

[9] Torres L, Neocleous K, Pilakoutas K. Design procedure and simplified equations for the flexural capacity of concrete members reinforced with fibre reinforced polymer bars. Structural Concrete 2012; 1;13(2):119-29.

[10] Kautsch R., Schnell J. Appliance of the extended technical bending theory in bridge design, Jure Redic (Editor): Bridges - Proceedings of the International Conference on Bridges, Dubrovnik, Croatia, 2006.

[11] Visintin P., Oehlers D. J. Mechanics closed form solutions for moment redistribution of RC beams. Structural Concrete 2016; doi:10.1002/suco.201500085

[12] Kuo W, Cheng T. Hwang S. Force transfer mechanism and shear strength of reinforced concrete beams. Engineering Structures 2010; 32(6):1537-46.

[13] Kim J, Mander J. Influence of transverse reinforcement on elastic shear stiffness of cracked concrete elements. Engineering Structures 2007; 29(8):1798-807.

[14] Pan Z, Li B, Lu Z. Effective shear stiffness of diagonally cracked reinforced concrete beams. Engineering Structures 2014; 59:95-103.

[15] Baghi H. Shear strengthening of reinforced concrete beams with SHCC-FRP panels. Ph.D. Thesis, Portugal: University of Minho; 2015.

[16] Li B, Tran C. Reinforced concrete beam analysis supplementing concrete contribution in truss models. Engineering Structures 2008; 30(11):3285-94.

[17] Bentz E, Vecchio F. Collins M. Simplified modified compression field theory for calculating shear strength of reinforced concrete elements. ACI Structural Journal 2006; 103(2):614-24.

[18] Vecchio F, Collins M. The modified compression field theory for reinforced concrete elements subjected to shear. ACI Journal 1986; 83(2):219-31.

[19] Ghali A, Neville A, Brown T. Structural analysis a unified classical and matrix approach. Fifth edition, Spon Press; 2003.

[20] Barros J, Dalfré G. A model for the prediction of the behaviour of continuous RC slabs flexurally strengthened with CFRP systems. 11th International Symposium on Fiber Reinforced Polymer Reinforcement for Concrete Structures. Portugal; 2013.

[21] Barros J, Ferreira D, Fortes A, Dias S. Assessing the effectiveness of embedding CFRP laminates in the near surface for structural strengthening. Construction and Building Materials 2006; 20:478-491.

[22] Rajendra K. Numerical models for the simulation of the cyclic behaviour of RC structures incorporating new advanced materials. Ph.D. Thesis, Portugal: University of Minho; 2012. 
[23] Walraven J. Aggregate interlock: a theoretical and experimental analysis. Ph.D. Thesis, Netherlands: Delft University of Technology; 1980.

[24] Nooru-Mohamed M. Mixed-mode fracture of concrete: an experimental approach. Ph.D. Thesis, Netherlands: Delft University of Technology; 1992.

[25] ACI-ASCE committee 426. Shear strength of reinforced concrete member. (ACI 426R-74), Proceedings ASCE, V.99 No.ST6 1973; 1148-1157.

[26] Yildirim V. Vibration behaviour of composite beams with rectangular sections considering the different shear correction factors. Vibration problems ICOVP. Netherlands: Springer; 2005.[27] Yu Q., Le J.-L., Hubler M. H., Wendner R., Cusatis G., Bazant Z. Comparison of main models for size effect on shear strength of reinforced and prestressed concrete beams. Structural Concrete 2016; doi:10.1002/suco.201500126

[28] Rots J. Computational modeling of concrete fracture. Ph.D. Thesis, Netherlands: Delft University of technology; 1988.

[29] Hand F. A layered finite element nonlinear analysis of reinforced concrete plates and shells. Ph.D. Thesis, Illinois: University of Illinois; 1972.

[30] Barros J. Comportamento do betão reforçado com fibras. Análiseexperimental e simulação numérica. Behavior of fiber reinforced concrete. Experimental analysis and numerical simulation. PhD Thesis, Portugal: University of Porto; 1995. [In Portuguese]

[31] Kolmar W. Beschreibug der kraftubertragung uber risse in nichtlinearen finite-element-berechnungen von stahlbetontrag-werken. PhD Thesis, Darmstadt: Techn. Hochschule; 1985.

[32] Cervenka V, Pukl H, Eligehausen R. Computer simulation of anchoring technique and design of concrete structures. Proc. Second Intern. Conf. on Computer Aided Analysis and Design of Concrete Structures. Zell am See, Austria; 1990.

[33] Mehlhorn G. Some developments for finite element analysis of reinforced concrete structures. Proc. Second Intern. Conf. on Computer Aided Analysis and Design of Concrete Structures. Zell am See, Austria; 1990.

[34] EN1992-1-1. Design of concrete structures-Part 1-1: General rules and rules for buildings: Eurocode 2: de Normalisation, Comité Européen; 2004.

[35] Sena-Cruz J. Strengthening of concrete structures with near-surface mounted CFRP laminate strips. Ph.D. Thesis, Portugal: University of Minho; 2004.

[36] CEB design manual on cracking and deformations. Committee Euro-International du Beton, Bulletin D’Information $\mathrm{n}^{\circ}$ 158-E; 1985.

[37] Barris C, Torres L, Comas J, Mias C. Cracking and deflections in GFRP RC beams: an experimental study. Composites Part B: Engineering 2013; 55:580-90.

[38] Barros J, Dias S. Near surface mounted CFRP laminates for shear strengthening of concrete beams. Cement and Concrete Composites 2006; 28 (3): 276-292.

[39] Panda K, Bhattacharyya S, Barai S. Effect of transverse steel on the performance of RC T-beams strengthened in shear zone with GFRP sheet. Construction and Building Materials 2013; 41:79-90.[40] Debernardi PG, Taliano M. Shear deformation in reinforced concrete beams with thin web. Magazine of Concrete Research. 2006; 58(3):157-72.

[41] Perkins S. Shear behaviour of deep reinforced concrete members subjected to uniform load. Master of Applied Science Thesis, Canada: University of Toronto; 2011.

[42] CEB-FIP. "Model code 2010: Final draft." Fédération Internationale du Béton fib/International Federation for Structural Concrete (du Béton, Fédération Internationale), Lausanne, Switzerland, 2010. 
Table 1: Geometry, reinforcement details and main material properties of specimens SP1 and SP2

\begin{tabular}{|lcccccccccc|}
\hline $\begin{array}{l}\text { Tested } \\
\text { beams }\end{array}$ & $\begin{array}{c}L \\
(\mathrm{~mm})\end{array}$ & $\begin{array}{c}b_{w} \\
(\mathrm{~mm})\end{array}$ & $\begin{array}{c}h \\
(\mathrm{~mm})\end{array}$ & $\begin{array}{c}d_{s} \\
(\mathrm{~mm})\end{array}$ & $a / d$ & $\begin{array}{c}\rho_{l} \\
(\%)\end{array}$ & $\begin{array}{c}\rho_{w} \\
(\%)\end{array}$ & $\begin{array}{c}f_{c} \\
(\mathrm{Mpa})\end{array}$ & $\begin{array}{c}f_{y l} \\
(\mathrm{Mpa})\end{array}$ & $\begin{array}{c}f_{y t} \\
(\mathrm{Mpa})\end{array}$ \\
\hline SP1 & 1800 & 150 & 350 & 308 & 2.6 & 2.13 & 0.47 & 33 & 440 & 370 \\
SP2 & 1800 & 150 & 350 & 308 & 2.6 & 2.13 & 0.31 & 33 & 440 & 370 \\
\hline & :length of the beam; $b_{w}$ :the web thickness of the beam cross section; $h$ :the height of the beam cross section; $d_{s}$ \\
:internal arm of longitudinal tensile steel bars; $a / d:$ shear span to effective depth ratio,$\rho_{l}$ :ratio of area of \\
longitudinal reinforcement to beam effective sectional area; $\rho_{w}$ :ratio of stirrup area to web area $f_{c}$ :compressive \\
strength of concrete; $f_{y l}$ :yielding stress of longitudinal reinforcing steel; $f_{y t}$ :yielding stress of stirrups steel
\end{tabular}
628 
Table 2: Geometry, reinforcement details and main material properties of specimens SP3 and SP4

\begin{tabular}{|c|c|c|c|c|c|c|c|c|c|c|}
\hline $\begin{array}{l}\text { Tested } \\
\text { beams }\end{array}$ & $\begin{array}{c}L \\
(\mathrm{~mm})\end{array}$ & $\begin{array}{c}b_{w} \\
(\mathrm{~mm})\end{array}$ & $\begin{array}{c}h \\
(\mathrm{~mm})\end{array}$ & $\begin{array}{c}d_{s} \\
(\mathrm{~mm})\end{array}$ & $a / d$ & $\begin{array}{l}\rho_{l} \\
(\%)\end{array}$ & $\begin{array}{l}\rho_{w} \\
(\%)\end{array}$ & $\begin{array}{c}f_{c} \\
(\mathrm{Mpa})\end{array}$ & $\begin{array}{c}f_{y l} \\
(\mathrm{Mpa})\end{array}$ & $\begin{array}{c}f_{y t} \\
(\mathrm{Mpa})\end{array}$ \\
\hline & & & & & & & & & & \\
\hline SP4 & 900 & 150 & 100 & 125 & 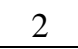 & & 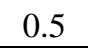 & 49.5 & $5 / 1$ & 540 \\
\hline \multicolumn{11}{|c|}{$\begin{array}{l}L \text { :length of the beam; } b_{w} \text { :the web thickness of the beam cross section; } h \text { :the height of the beam cross section; } d_{s} \\
\text { :internal arm of longitudinal tensile steel bars; } a / d \text { : shear span to effective depth ratio }, \rho_{l} \text { :ratio of area of } \\
\text { longitudinal reinforcement to beam effective sectional area; } \rho_{w} \text { :ratio of stirrup area to web area } f_{c} \text { :compressive } \\
\text { strength of concrete; } f_{y l} \text { :yielding stress of longitudinal reinforcing steel; } f_{y t} \text { :yielding stress of stirrups steel }\end{array}$} \\
\hline
\end{tabular}
630 
Table 3: Geometry, reinforcement details and main material properties of specimens SP5 and SP6

\begin{tabular}{|c|c|c|c|c|c|c|c|c|c|c|c|c|}
\hline $\begin{array}{l}\text { Tested } \\
\text { T-beams }\end{array}$ & $\begin{array}{c}L \\
(\mathrm{~mm})\end{array}$ & $\begin{array}{c}b_{w} \\
(\mathrm{~mm})\end{array}$ & $\begin{array}{c}b_{f} \\
(\mathrm{~mm})\end{array}$ & $\begin{array}{c}h \\
(\mathrm{~mm})\end{array}$ & $\begin{array}{c}h_{f} \\
(\mathrm{~mm})\end{array}$ & $\begin{array}{c}d_{s} \\
(\mathrm{~mm})\end{array}$ & $a / d$ & $\begin{array}{l}\rho_{l} \\
(\%)\end{array}$ & $\begin{array}{l}\rho_{w} \\
(\%)\end{array}$ & $\begin{array}{c}f_{c} \\
(\mathrm{Mpa})\end{array}$ & $\begin{array}{c}f_{y l} \\
(\mathrm{Mpa})\end{array}$ & $\begin{array}{c}f_{y t} \\
(\mathrm{Mpa})\end{array}$ \\
\hline & & & & & & & & & & & & \\
\hline SP & 2200 & & & & 0 & & 5.2 & & & 72.0 & 30 & \\
\hline \multicolumn{13}{|c|}{$\begin{array}{l}L \text { :length of the beam; } b_{w} \text { :the web thickness of the beam cross section; } b_{f} \text { :the flange thickness of the beam cross section; } h \text { :the height of } \\
\text { the beam cross section; } h_{f} \text { :the flange thickness of the beam cross section; } d_{s} \text { :internal arm of longitudinal tensile steel bars; } a / d: \text { shear } \\
\text { span to effective depth ratio, } \rho_{l} \text { :ratio of area of longitudinal reinforcement to beam effective sectional area; } \rho_{w}: \text { ratio of stirrup area to } \\
\text { web area } f_{c} \text { :compressive strength of concrete; } f_{y l} \text { :yielding stress of longitudinal reinforcing steel; } f_{y t} \text { :yielding stress of stirrups steel }\end{array}$} \\
\hline
\end{tabular}

632 
634 Table 4: Geometry, reinforcement details and main material properties of specimens SP7

\begin{tabular}{|c|c|c|c|c|c|c|c|c|c|c|c|c|}
\hline $\begin{array}{c}\text { Tested } \\
\text { I-beams }\end{array}$ & $\begin{array}{c}L \\
(\mathrm{~mm})\end{array}$ & $\begin{array}{c}b_{w} \\
(\mathrm{~mm})\end{array}$ & $\begin{array}{c}b_{f} \\
(\mathrm{~mm})\end{array}$ & $\begin{array}{c}h \\
(\mathrm{~mm})\end{array}$ & $\begin{array}{c}h_{f} \\
(m m)\end{array}$ & $\begin{array}{c}d_{s} \\
(\mathrm{~mm})\end{array}$ & $a / d$ & $\begin{array}{l}\rho_{l} \\
(\%)\end{array}$ & $\begin{array}{l}\rho_{w} \\
(\%)\end{array}$ & $\begin{array}{c}f_{c} \\
(\mathrm{Mpa})\end{array}$ & $\begin{array}{c}f_{y l} \\
(\mathrm{Mpa})\end{array}$ & $\begin{array}{c}f_{y t} \\
(\mathrm{Mpa})\end{array}$ \\
\hline SP7 & 7000 & 100 & 400 & 600 & 100 & 550 & 4.55 & 3.3 & 0.5 & 27.5 & 540 & 570 \\
\hline $\begin{array}{l}L \text { :length } \\
\text { the beam } \\
\text { to effectiv } \\
f_{c} \text { :comp }\end{array}$ & secti & $\begin{array}{l}w_{w}: \text { the } \\
h_{f}: \text { th }\end{array}$ & $\begin{array}{l}\text { thick } \\
\text { gge he }\end{array}$ & of th & $\mathrm{cros}$ & on; $d$ & Hnic & $\begin{array}{l}\text { ickne } \\
\text { of lo }\end{array}$ & dina & $\begin{array}{l}n \text { cross } \\
\text { sile ste }\end{array}$ & $\begin{array}{l}\text { on; } h \text { :t } \\
\text { s; } a / d\end{array}$ & $\begin{array}{l}\text { eight of } \\
\text { ar span }\end{array}$ \\
\hline
\end{tabular}

635

636 
Table 5: Geometry, reinforcement details and main material properties of specimens SP8

\begin{tabular}{|c|c|c|c|c|c|c|c|c|c|c|}
\hline $\begin{array}{l}\text { Tested } \\
\text { beams }\end{array}$ & $\begin{array}{c}L \\
(\mathrm{~mm})\end{array}$ & $\begin{array}{c}b_{w} \\
(\mathrm{~mm})\end{array}$ & $\begin{array}{c}h \\
(\mathrm{~mm})\end{array}$ & $\begin{array}{c}d_{s} \\
(\mathrm{~mm})\end{array}$ & $a / d$ & $\begin{array}{l}\rho_{l} \\
(\%)\end{array}$ & $\begin{array}{l}\rho_{w} \\
(\%)\end{array}$ & $\begin{array}{c}f_{c} \\
(\mathrm{Mpa})\end{array}$ & $\begin{array}{c}f_{y l} \\
(\mathrm{Mpa})\end{array}$ & $\begin{array}{c}f_{y t} \\
\text { Мpa) }\end{array}$ \\
\hline & & & & & & & & & 400 & - \\
\hline \multicolumn{11}{|c|}{$\begin{array}{l}L \text { :length of the beam; } b_{w} \text { :the web thickness of the beam cross section; } h \text { :the height of the beam cross section; } d_{s} \\
\text { :internal arm of longitudinal tensile steel bars; } a / d \text { : shear span to effective depth ratio, } \rho_{l} \text { :ratio of area of } \\
\text { longitudinal reinforcement to beam effective sectional area; } \rho_{w} \text { :ratio of stirrup area to web area } f_{c} \text { :compressive } \\
\text { strength of concrete; } f_{y l} \text { :yielding stress of longitudinal reinforcing steel; } f_{y t} \text { :yielding stress of stirrups steel }\end{array}$} \\
\hline
\end{tabular}



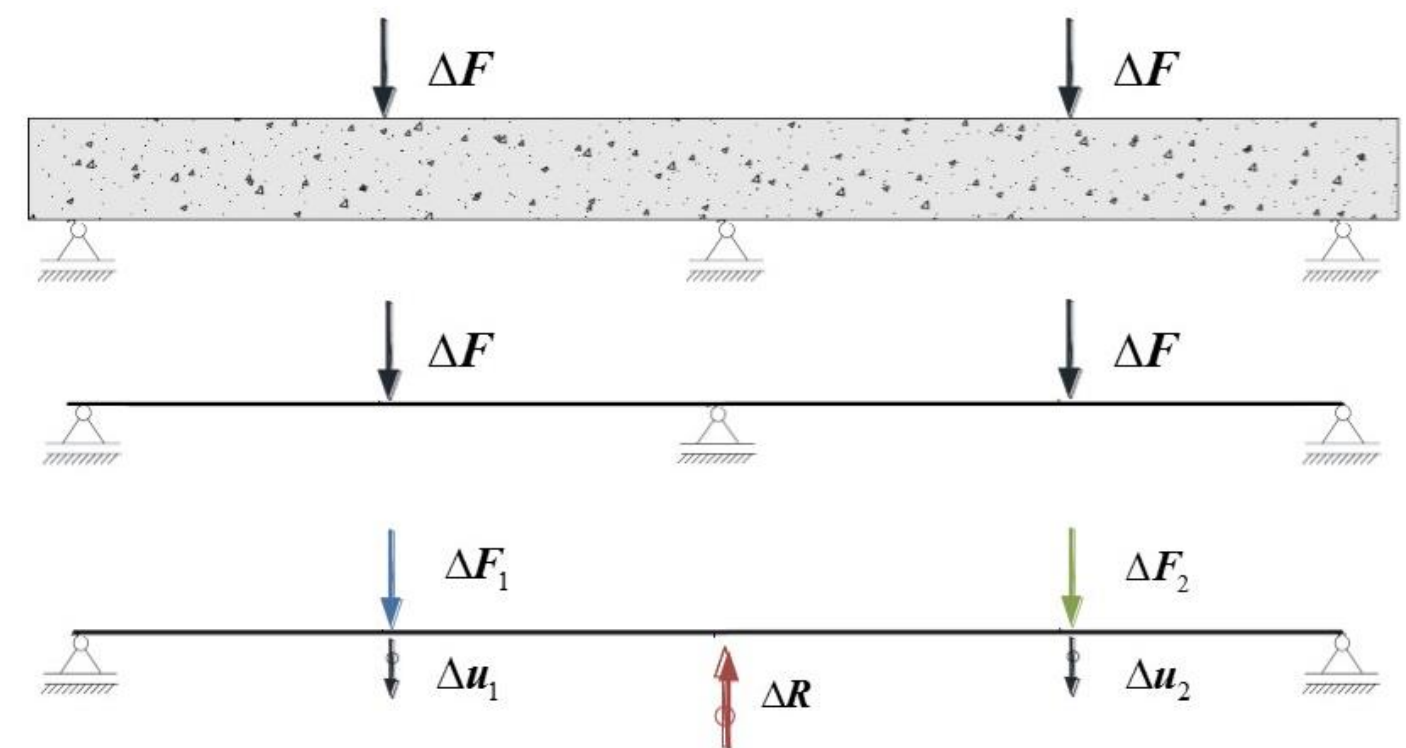

Figure 1: Statically indeterminate element with the representation of the imposed displacements, $\Delta u_{1}, \Delta u_{2}$ and 641 reaction $\Delta R$ 

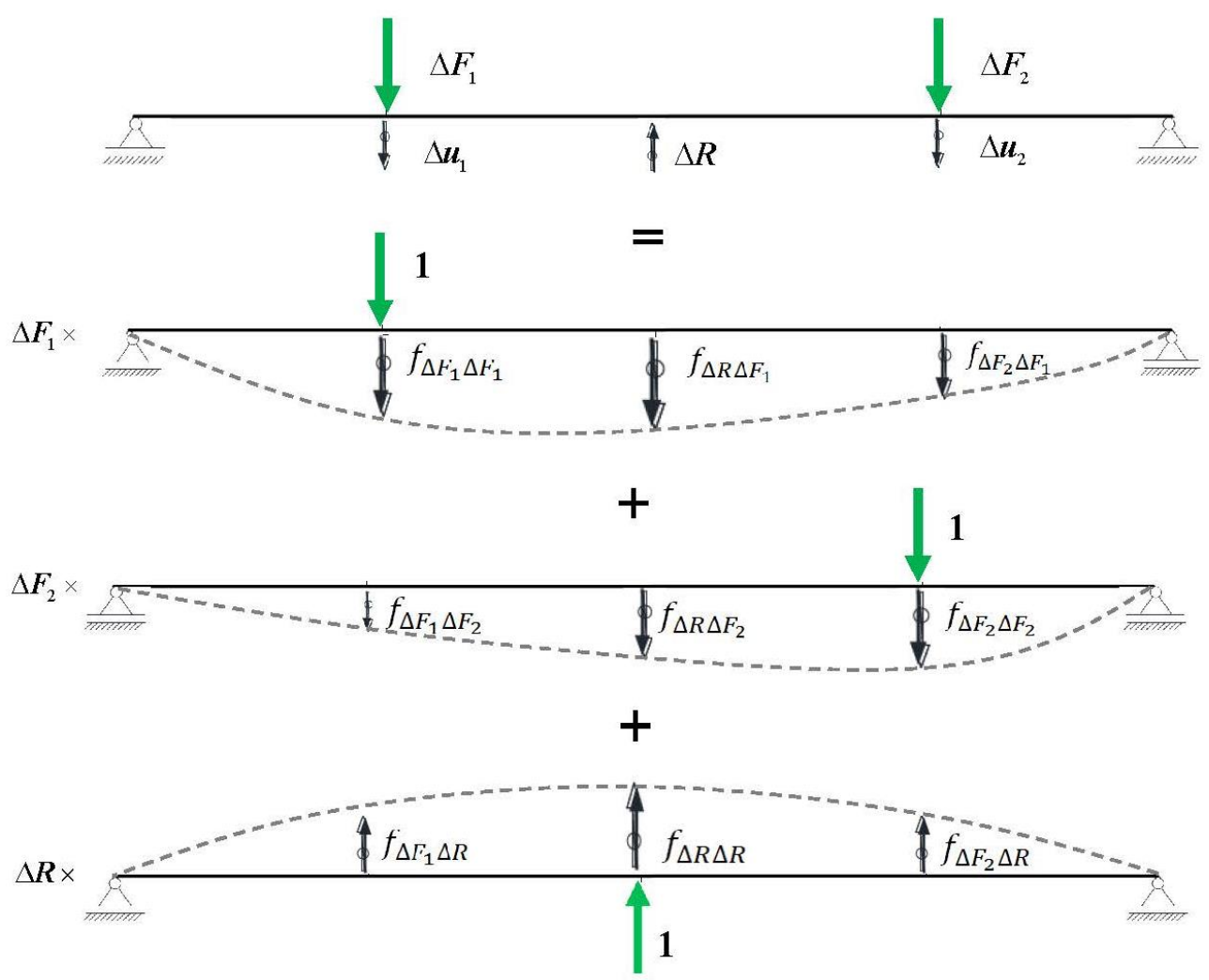

644

645 Figure 2: Physical meaning of the terms of the flexibility matrix, based on the displacements for each equilibrium 646 configuration 
(1)

$$
\Delta \underline{F}_{0}=\underline{I}^{\prime} \underline{M}_{0}=\underline{0}, \underline{F}_{0}=\underline{0}^{\prime} \underline{u}_{0}=\underline{0}
$$

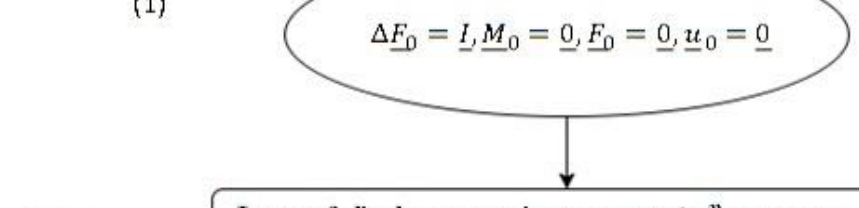

Loop of displacement increments $\Delta \underline{u}^{n}$ up to $\underline{u}_{\max }$

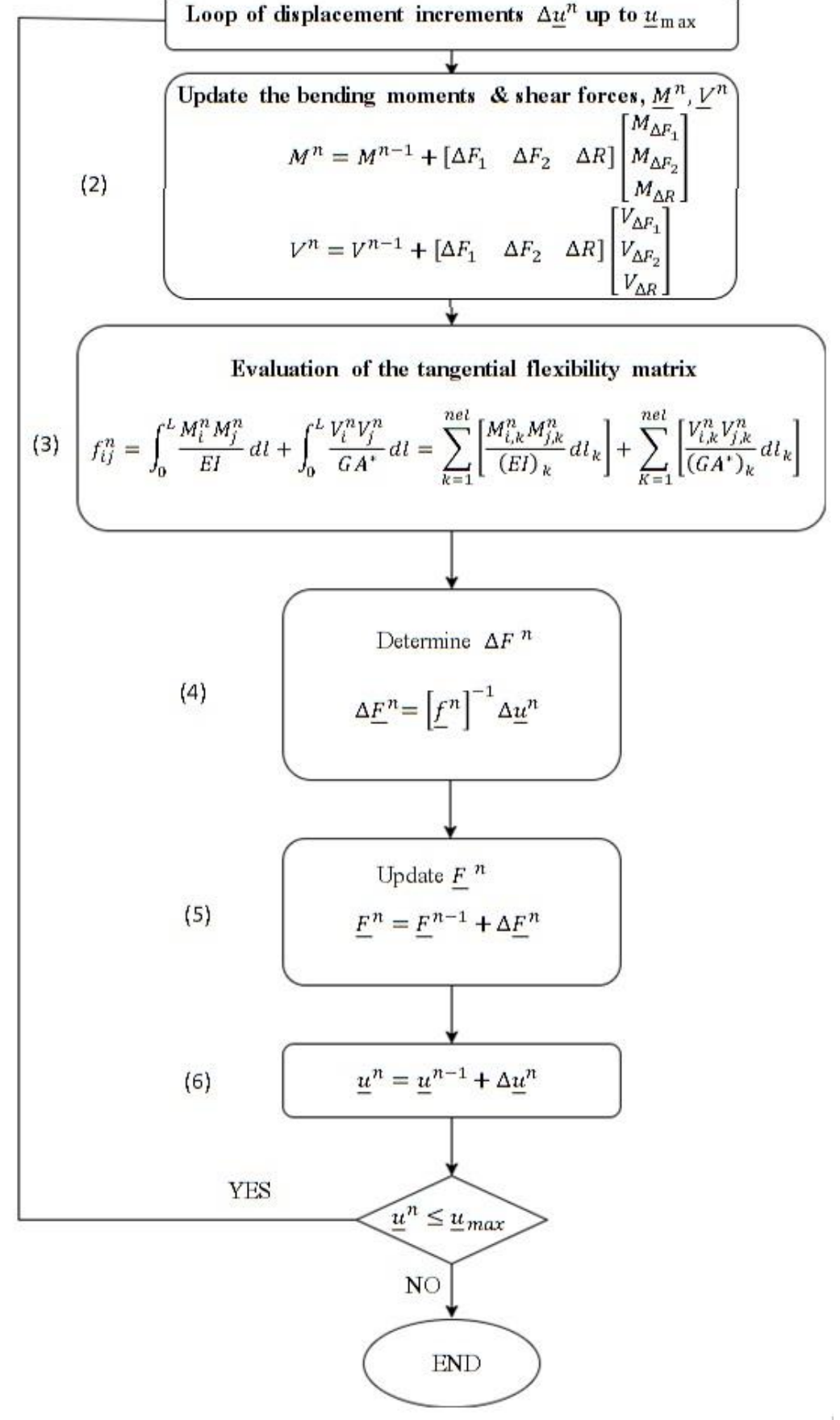

Figure 3: Algorithm to drive the force-deflection relationship 

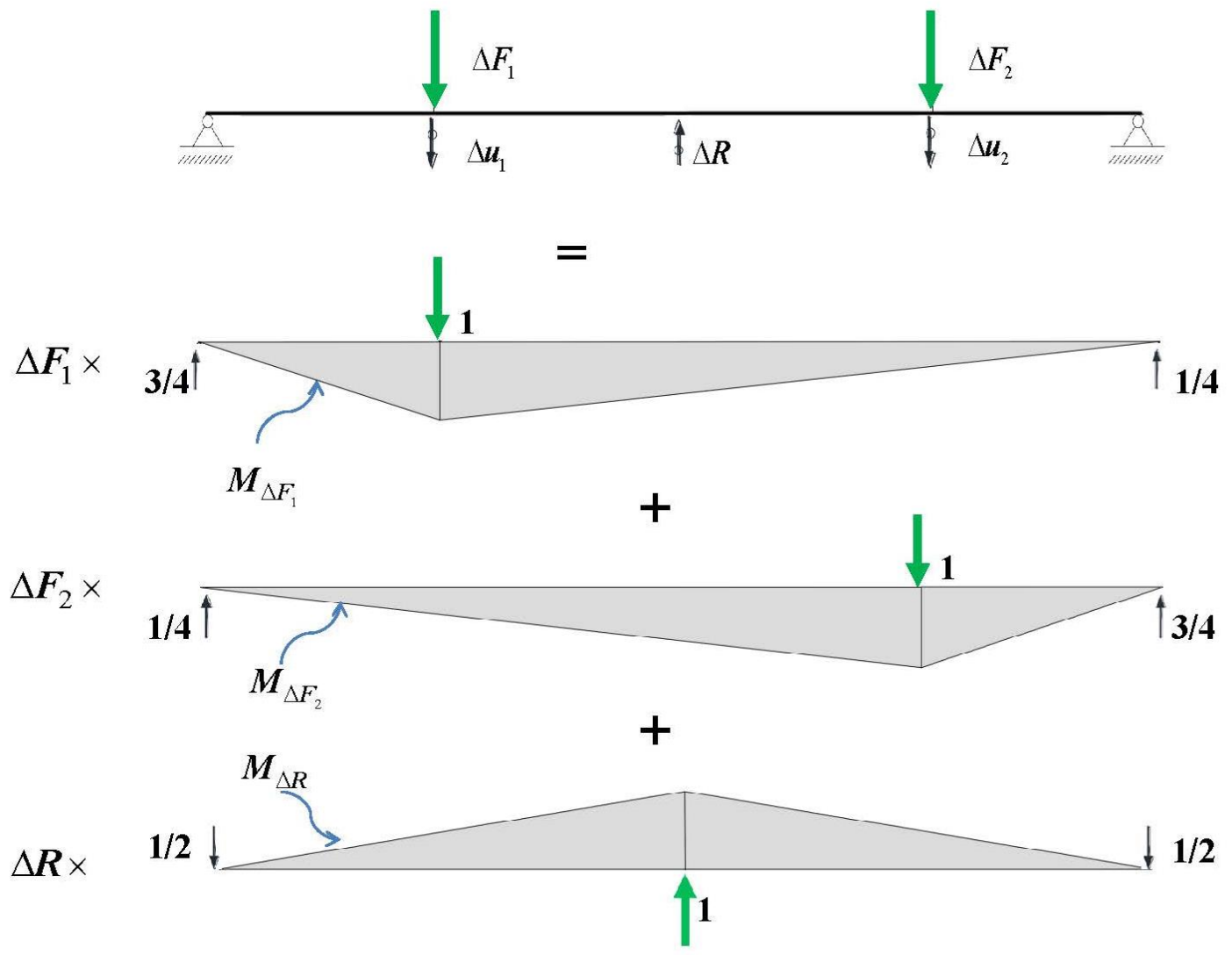

653

Figure 4: Terms of the flexibility matrix considering the flexure according to the superposition effects 655 


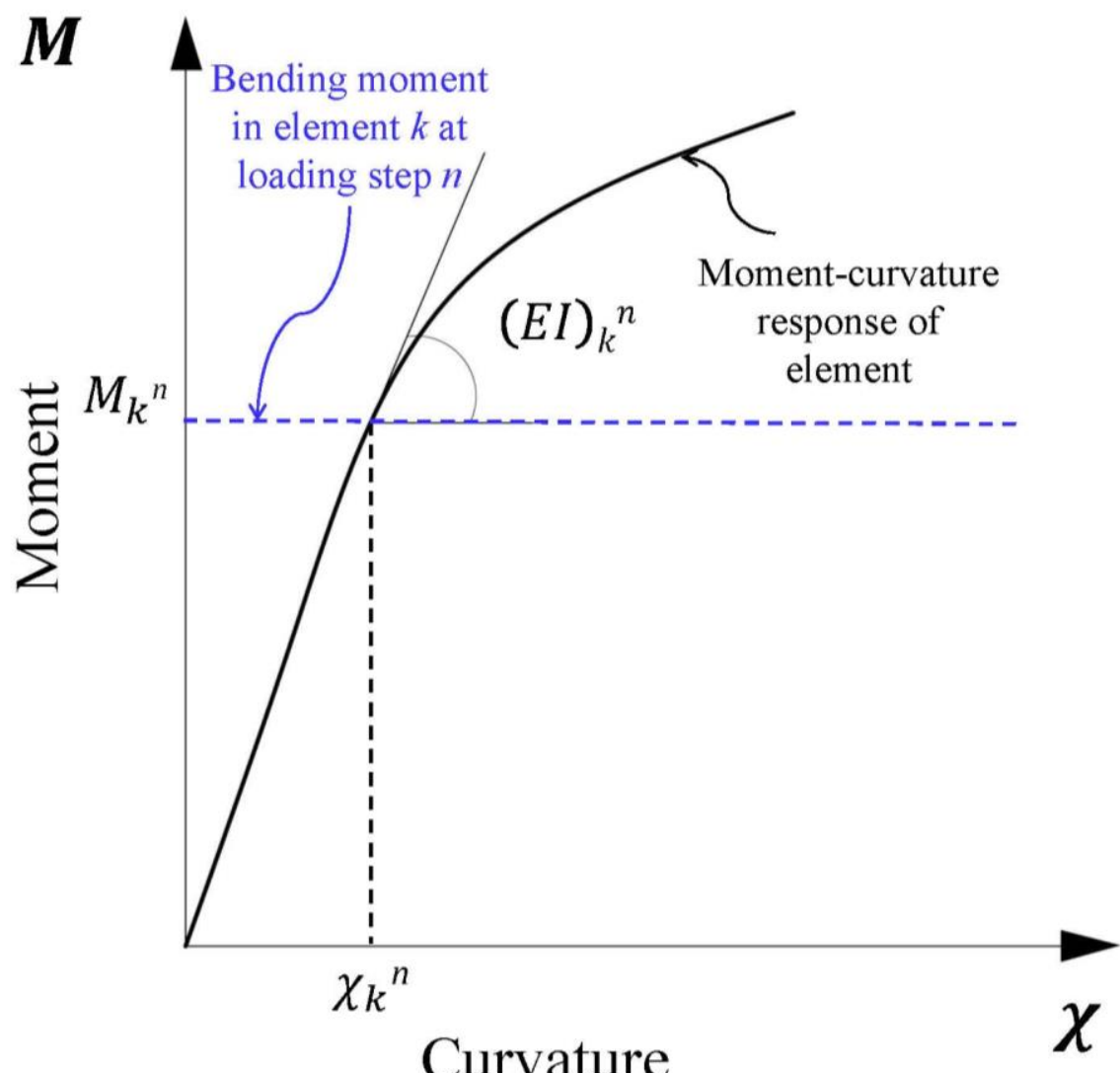




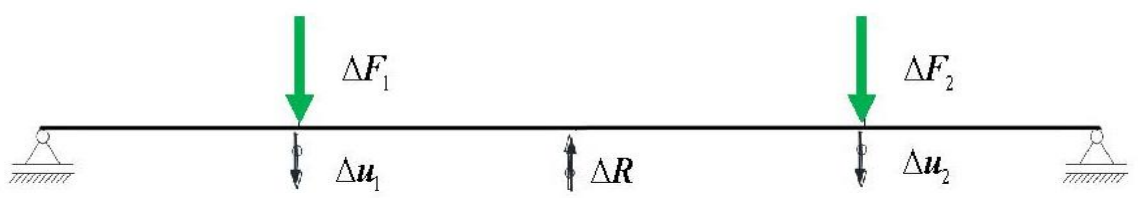

663

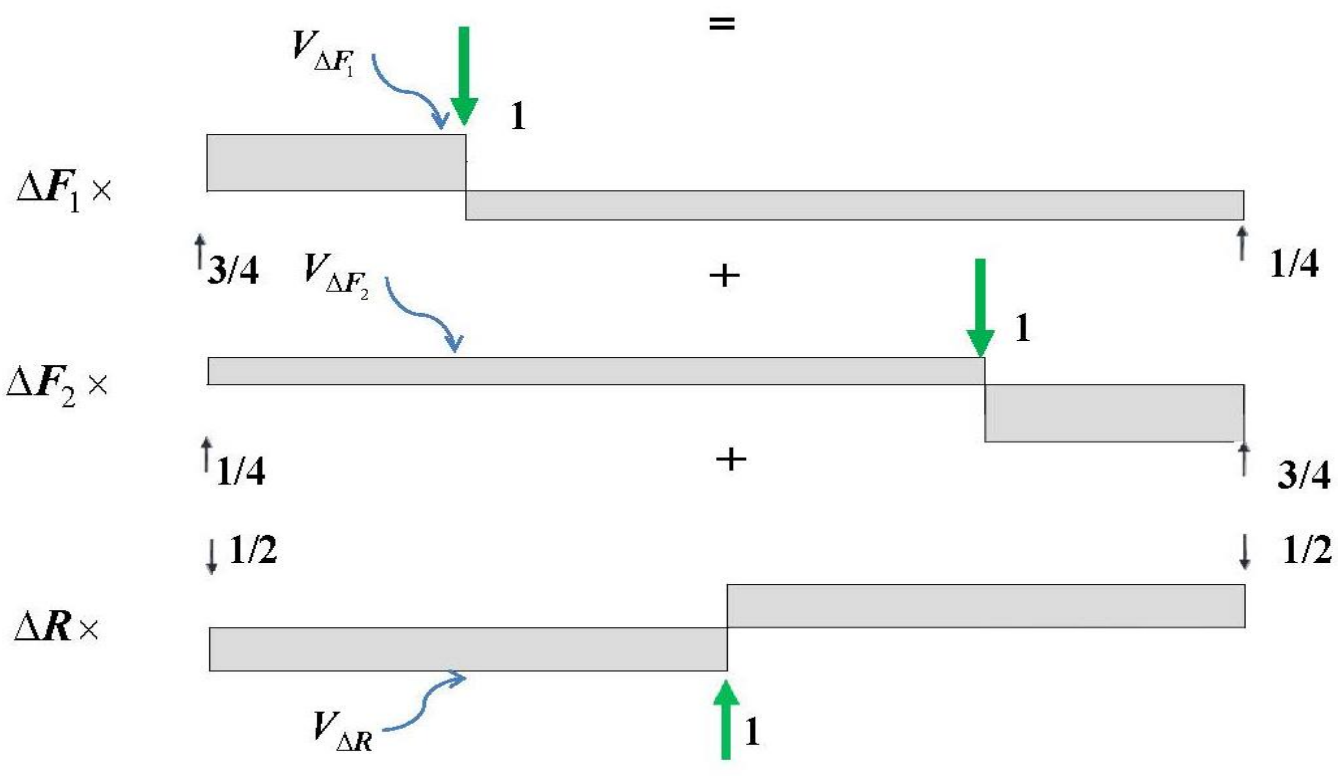

Figure 6: Terms of the flexibility matrix considering the shear according to the superposition effects 665 


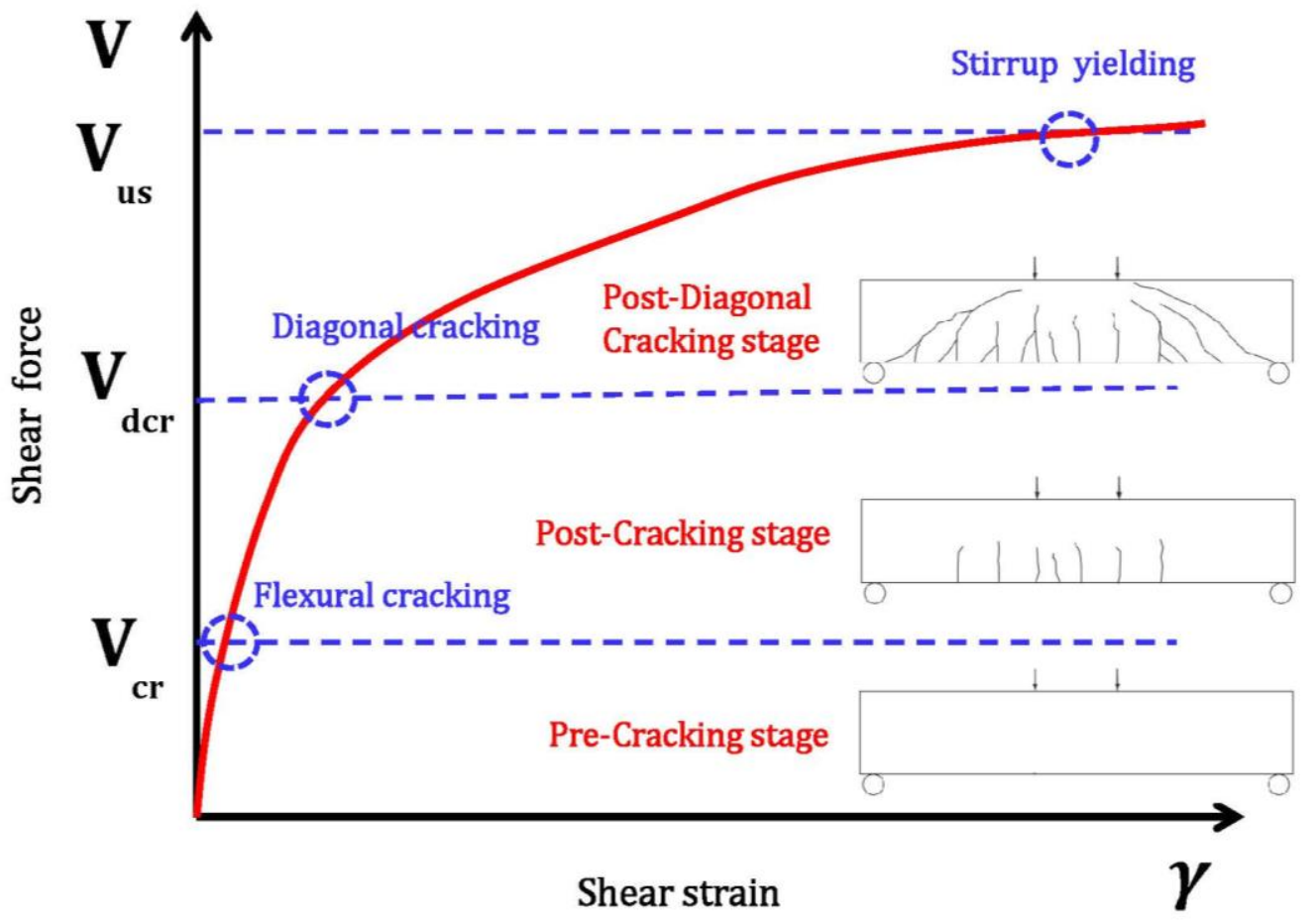




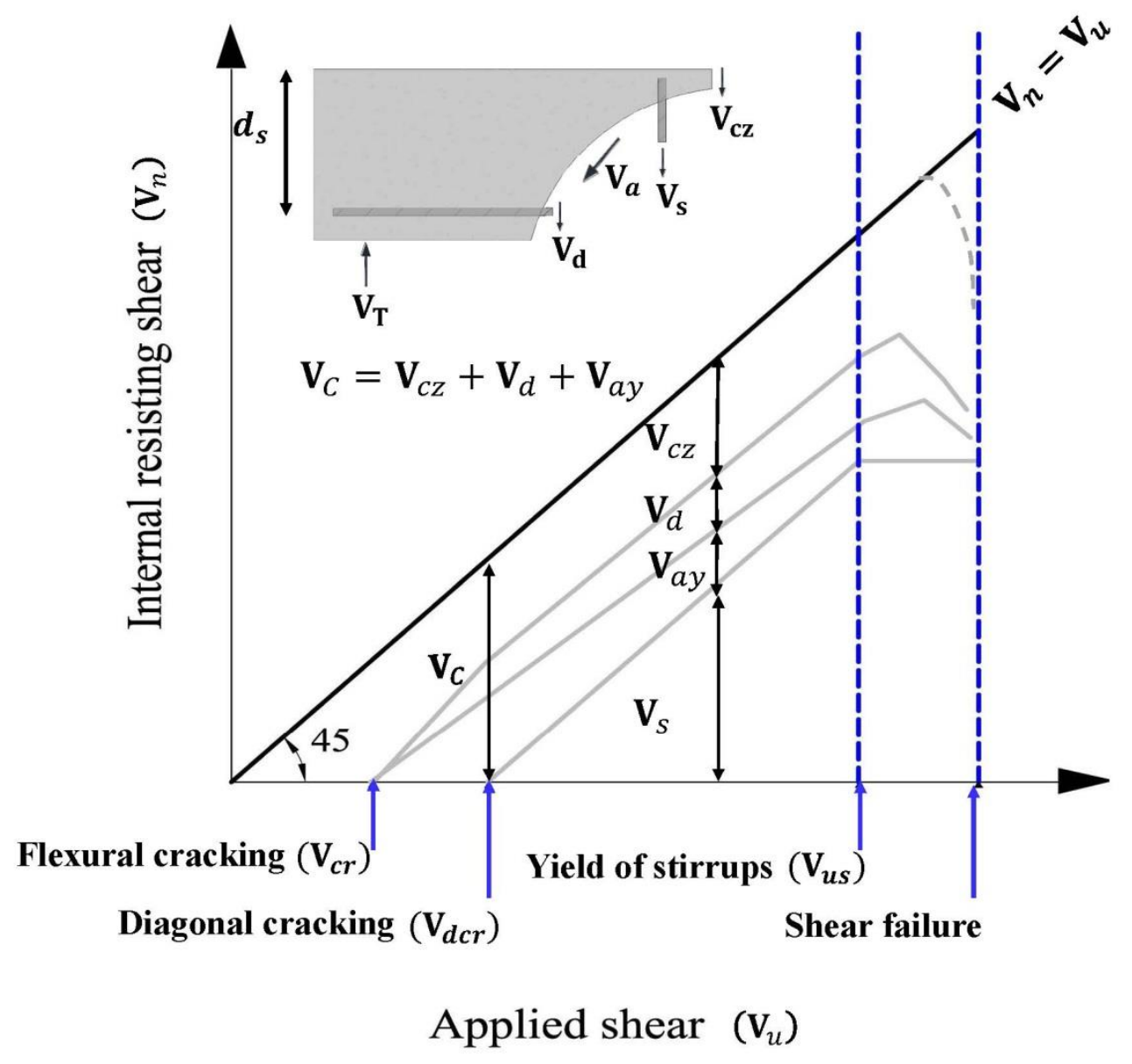




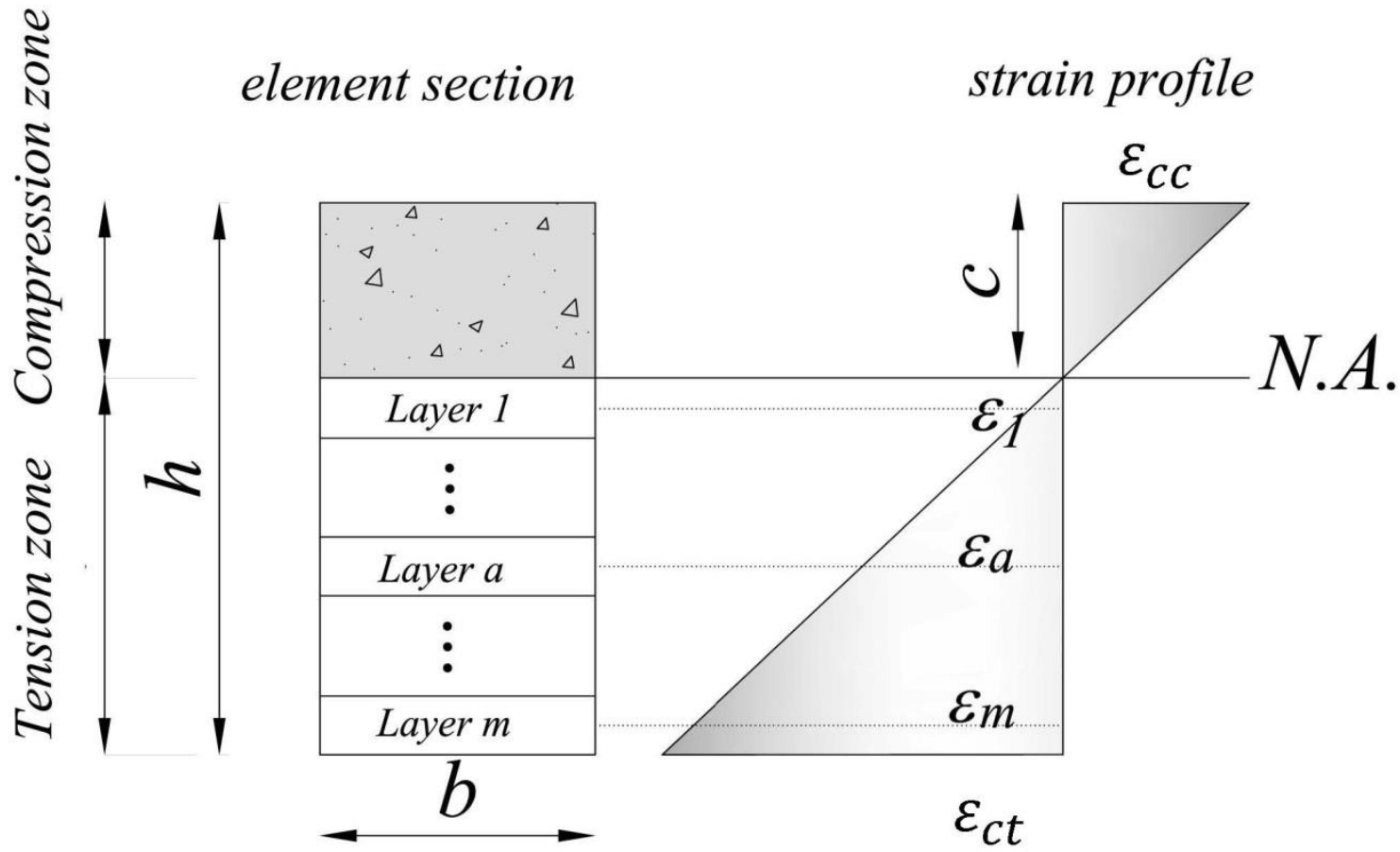

675

Figure 9: Schematic representation of longitudinal strain distribution for assisting on the determination of the shear 677 retention factor. 
$s_{x}=\max \left[0.9 d_{s}\right.$ or $\left.0.72 h\right]$

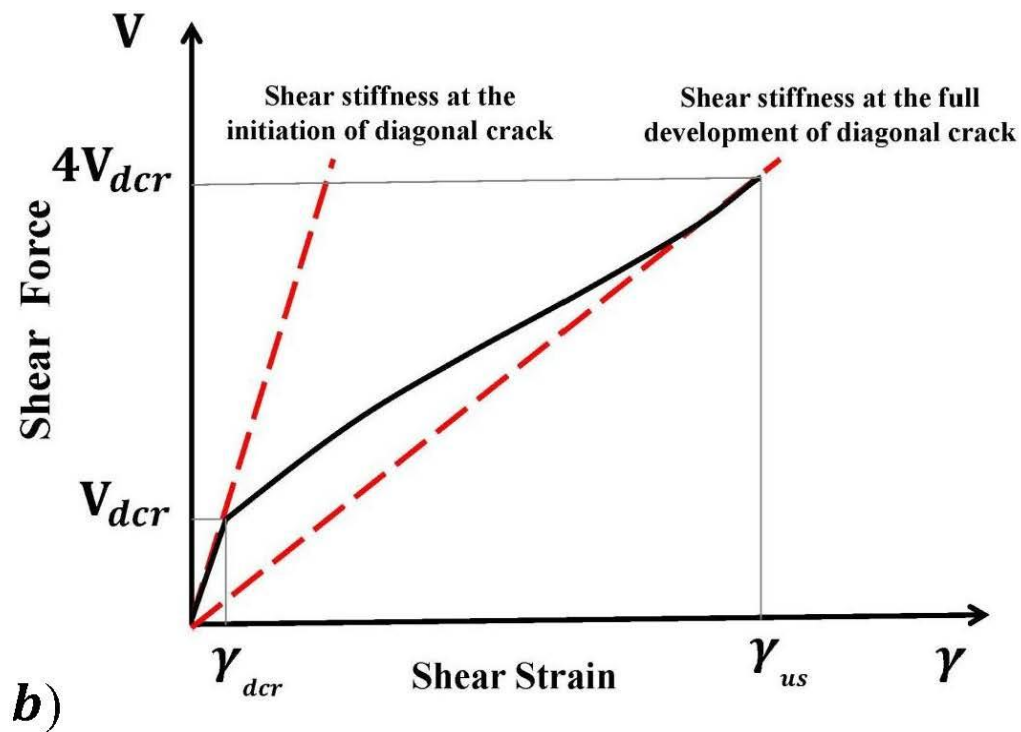




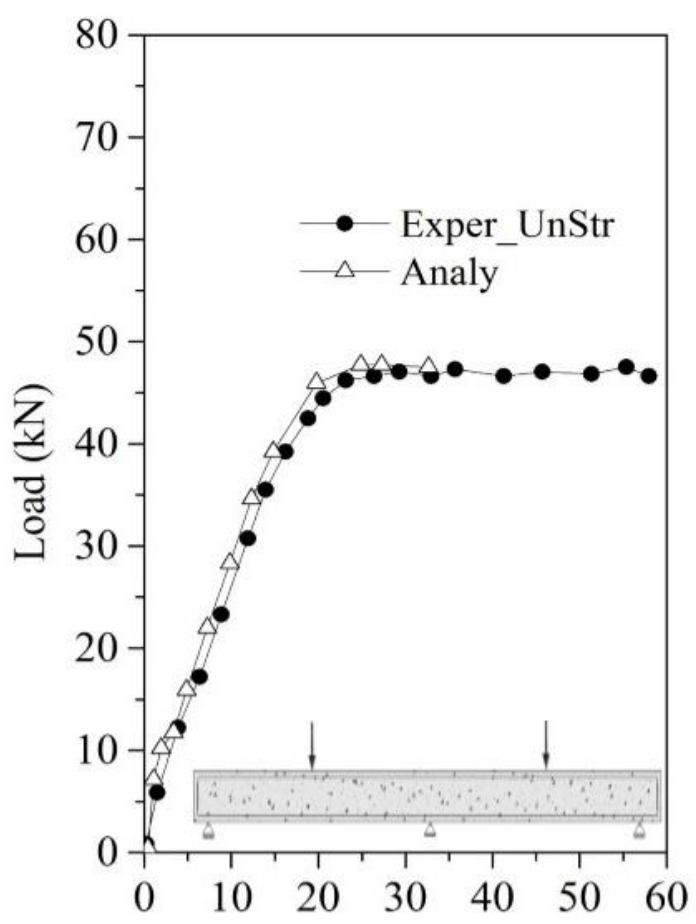

a) Slab deflection ( $\mathrm{mm}$ )

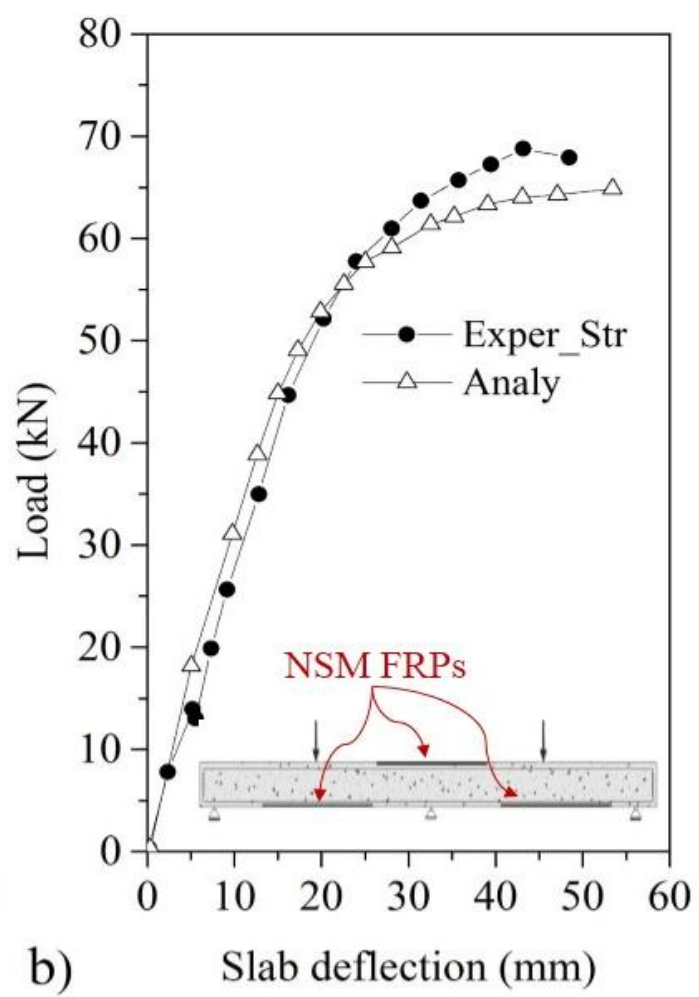

b)

\section{Slab deflection $(\mathrm{mm})$}

Figure 11: Analytical prediction of load-deflection relationships of: a) unstrengthened continuous slab, b) strengthened continuous slab 


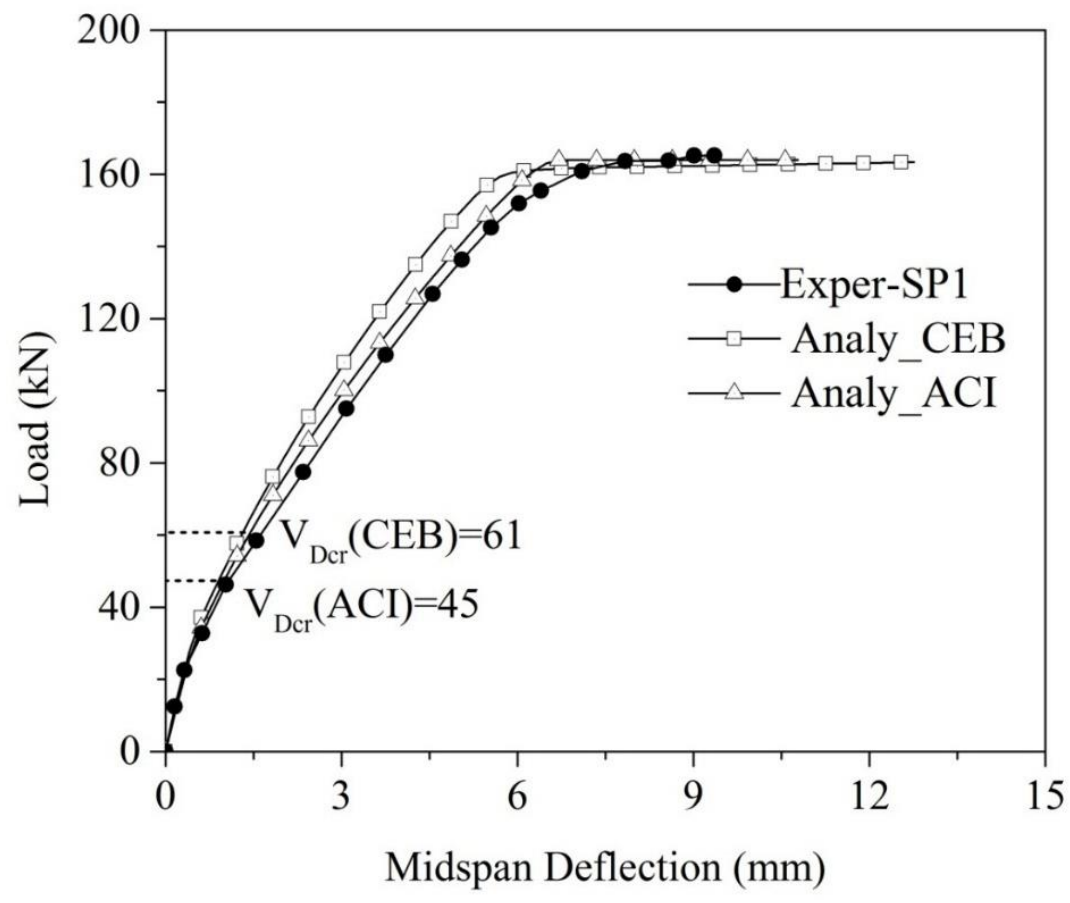

691

692 Figure 12: Analytical prediction of total load-deflection relationships of SP1 beam according to ACI and CEB 693 recommendations

694

695

696 


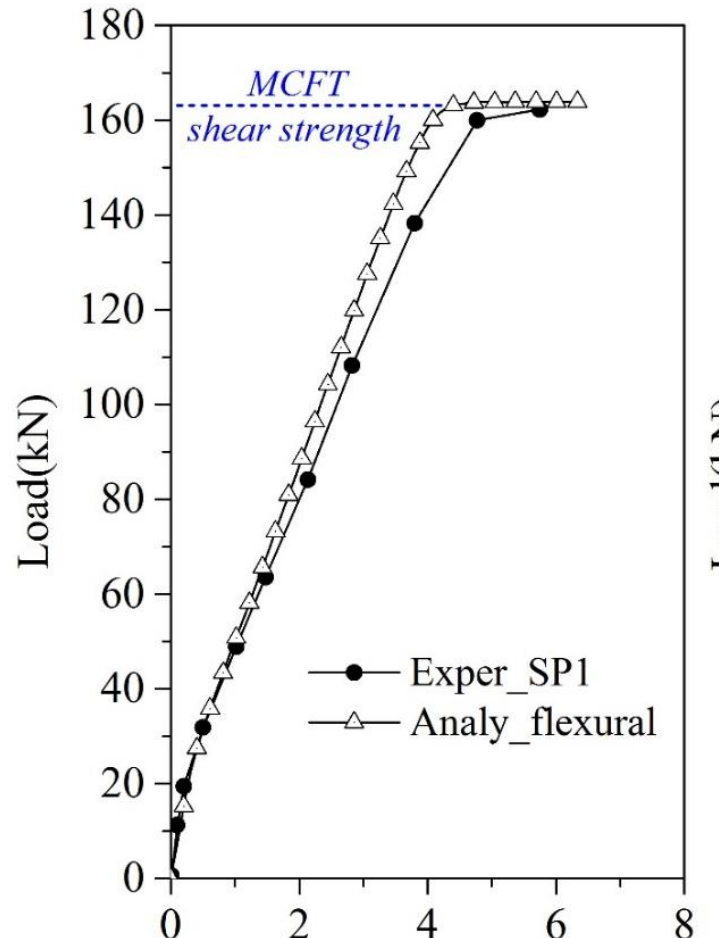

a)

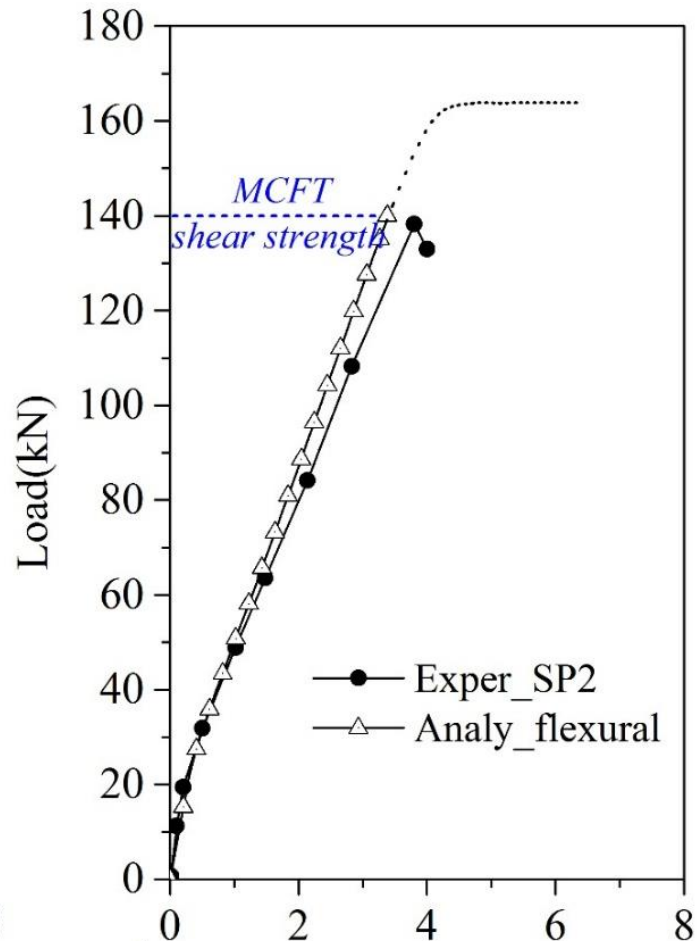

b) 

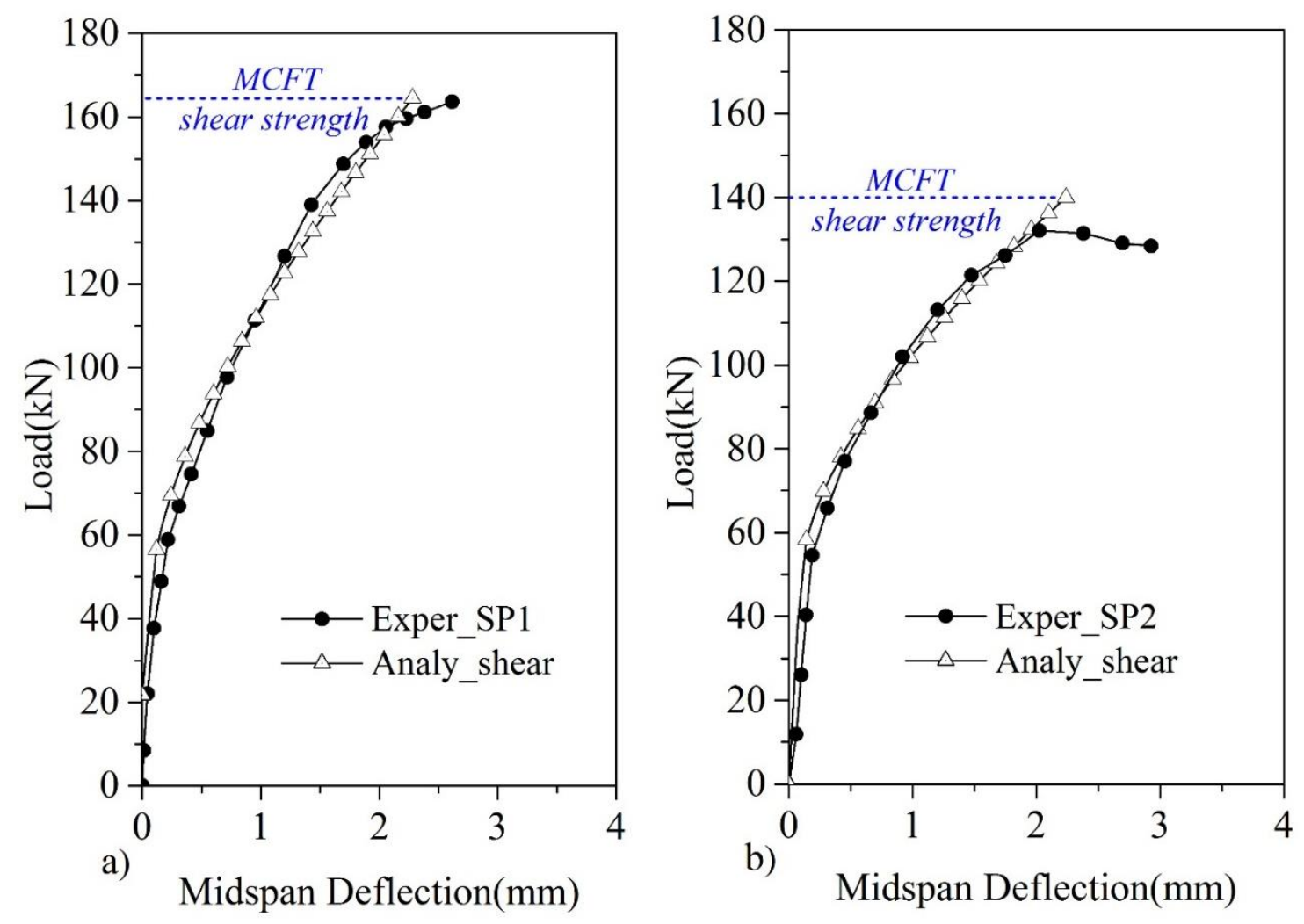

701

Figure 14: Analytical prediction of shear load-deflection relationships of: a) SP1 beam, b) SP2 beam 702 


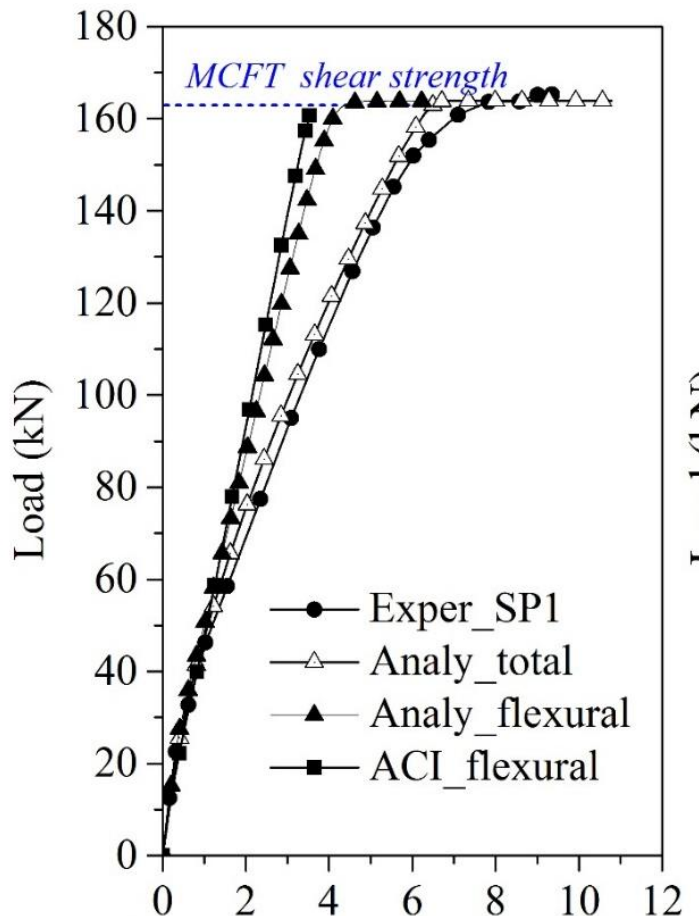

a)

Midspan deflection (mm)

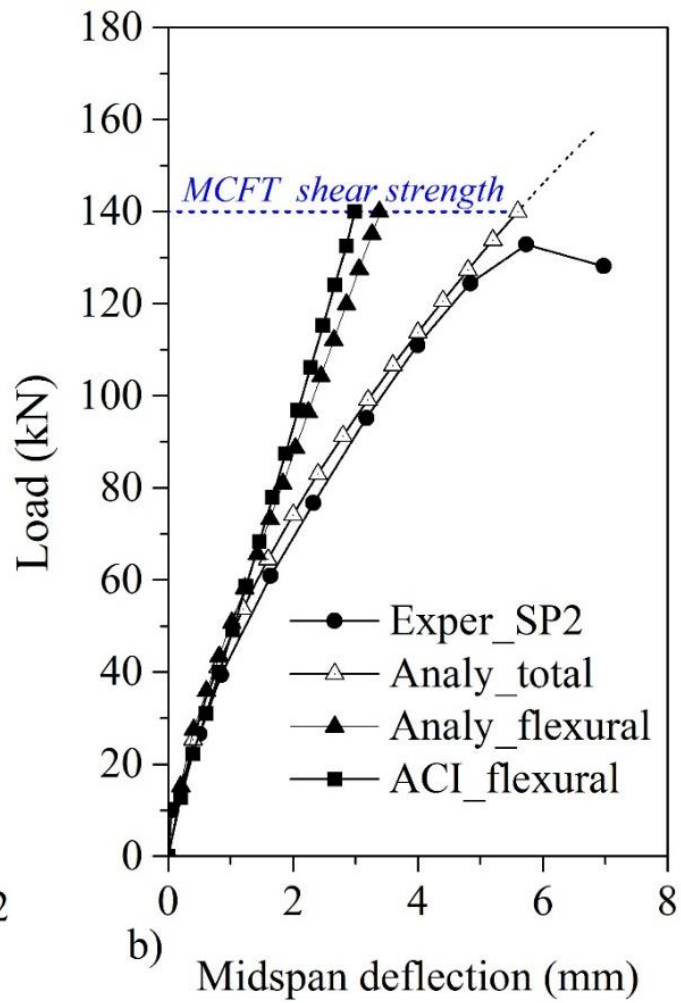

704

Figure 15: Analytical prediction of total load-deflection relationships of: a) SP1 beam, b) SP2 beam 


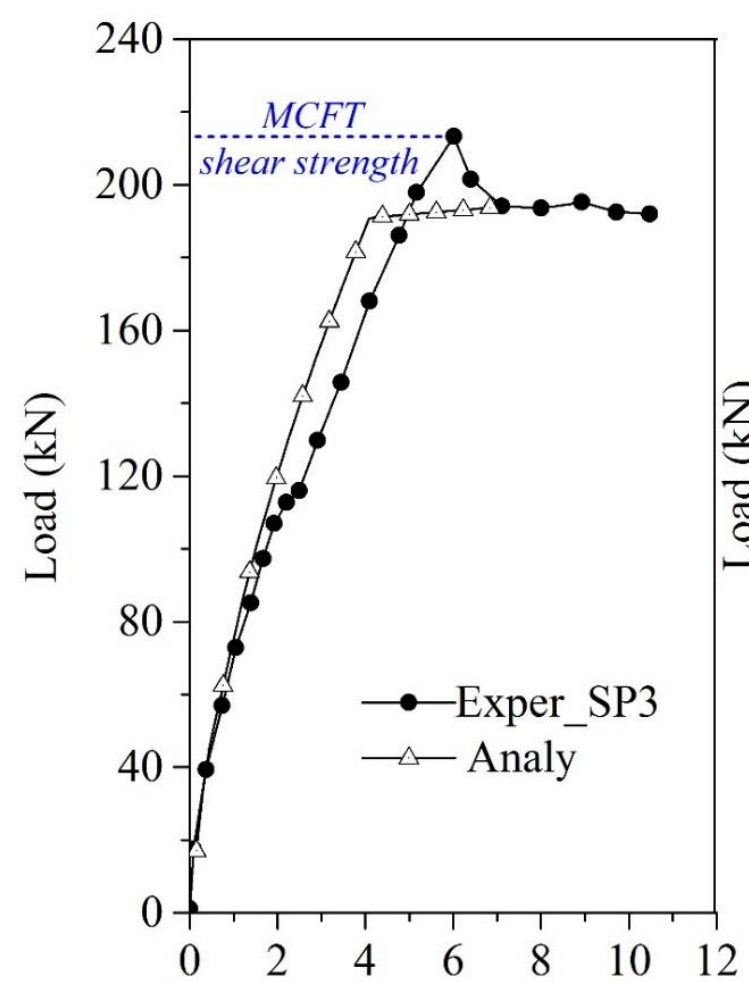

a)

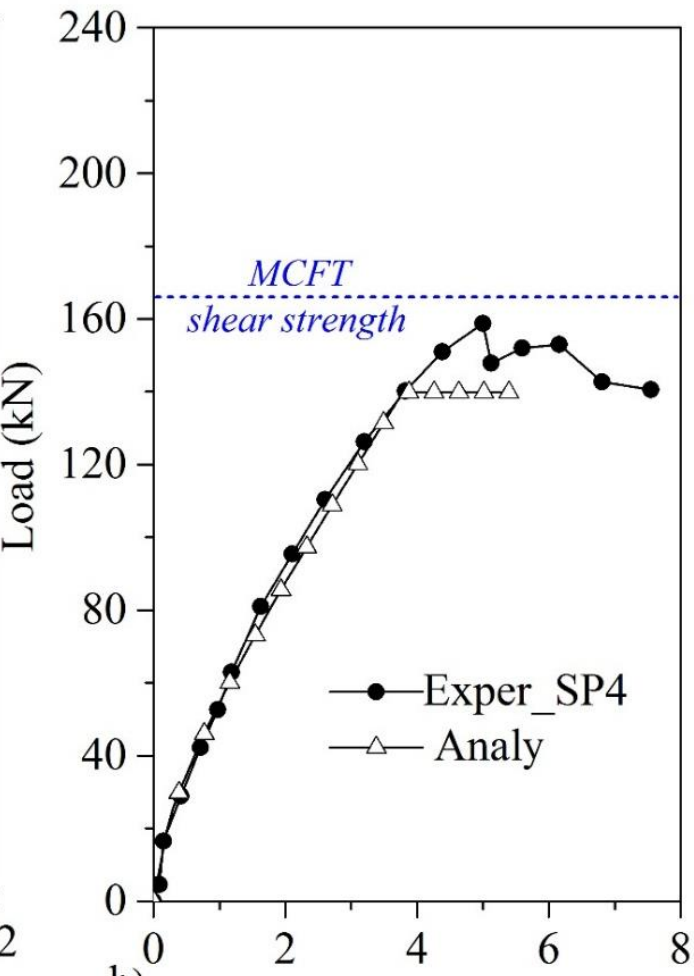

b) Midspan deflection (mm)

Figure 16: Analytical prediction of total load-deflection relationships of: a) SP3 beam, b) SP4 beam 


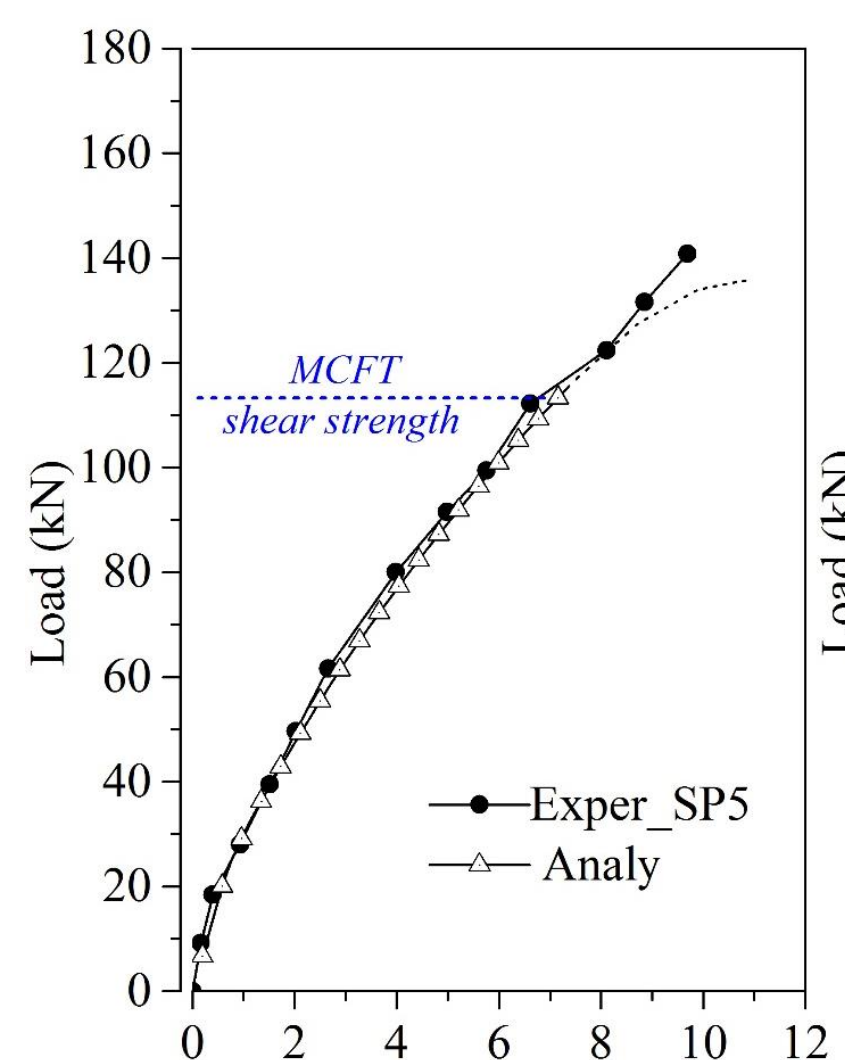

a) Midspan deflection (mm)

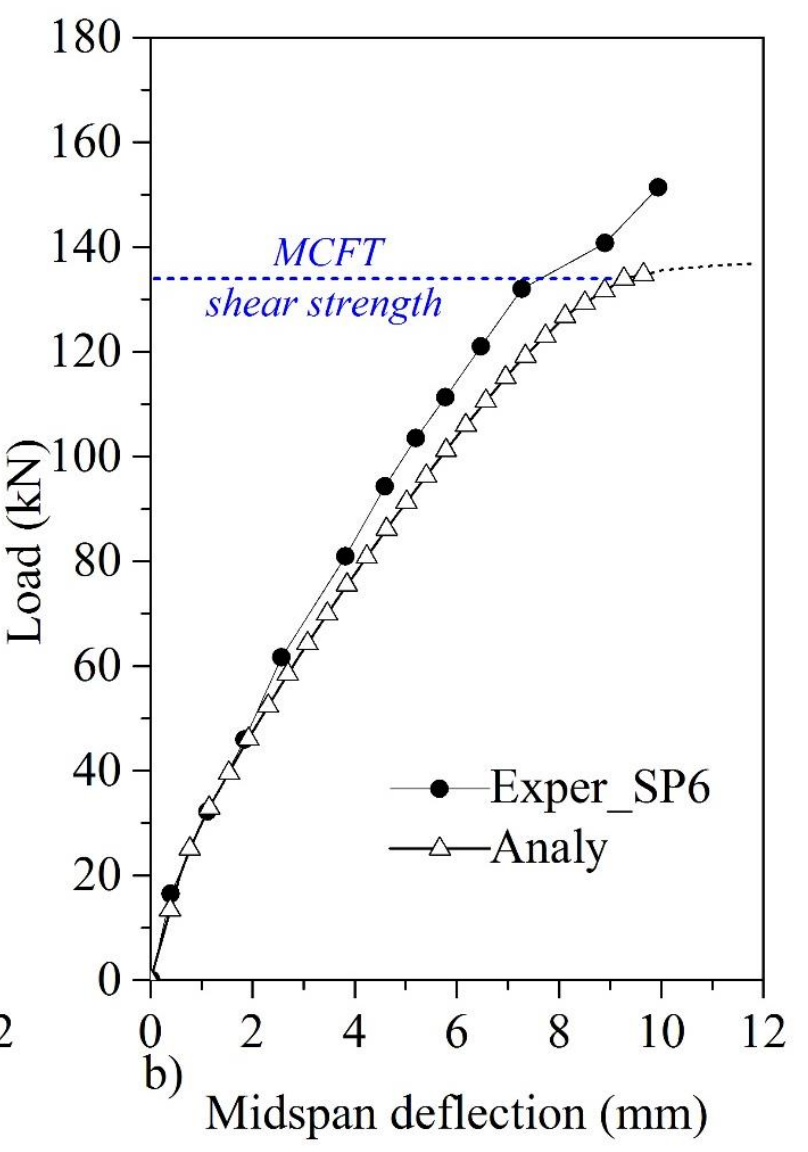

709

710

Figure 17: Analytical prediction of total load-deflection relationships of: a) SP5 beam, b) SP6 beam 


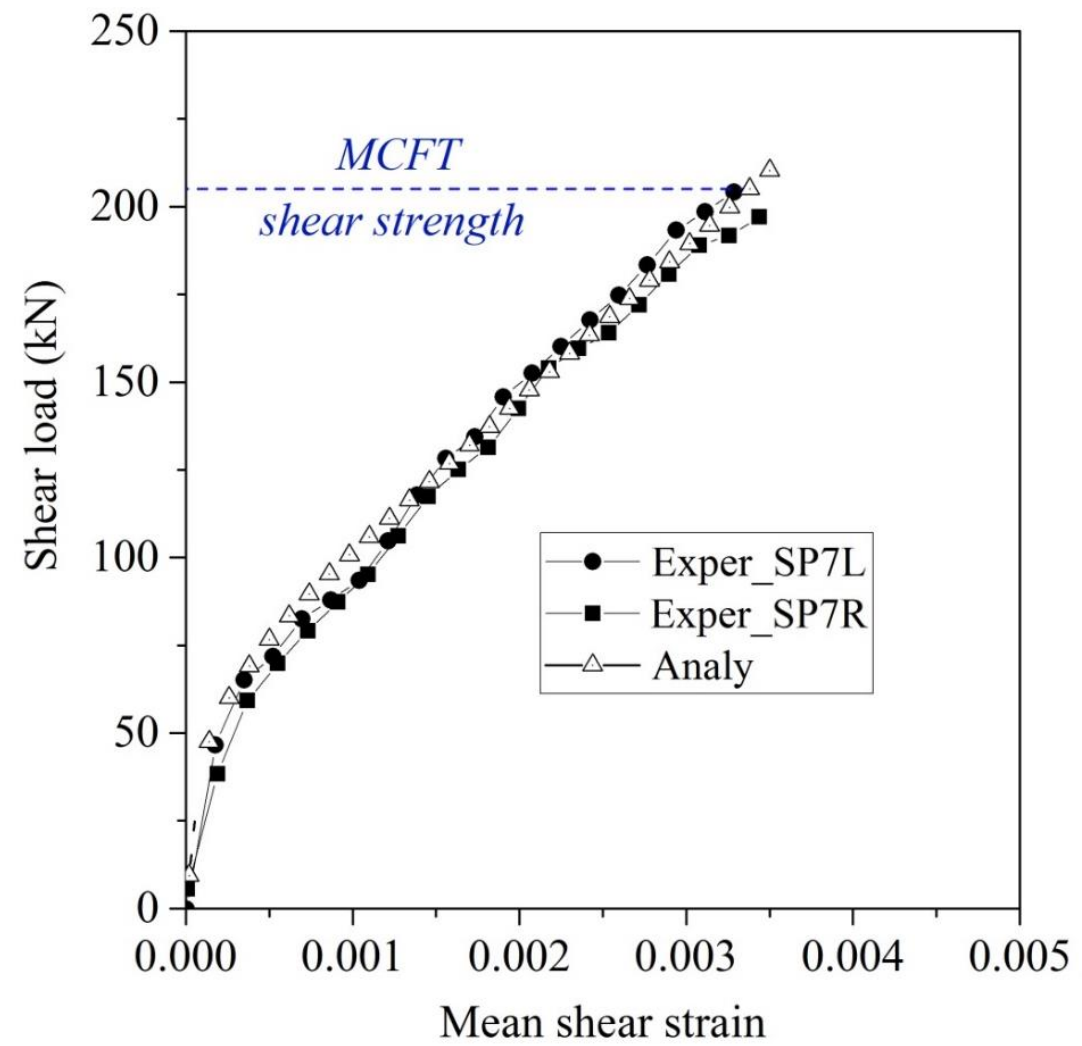

Figure 18: Analytical prediction of shear load-Mean shear strain relationships of SP7 beam 712 


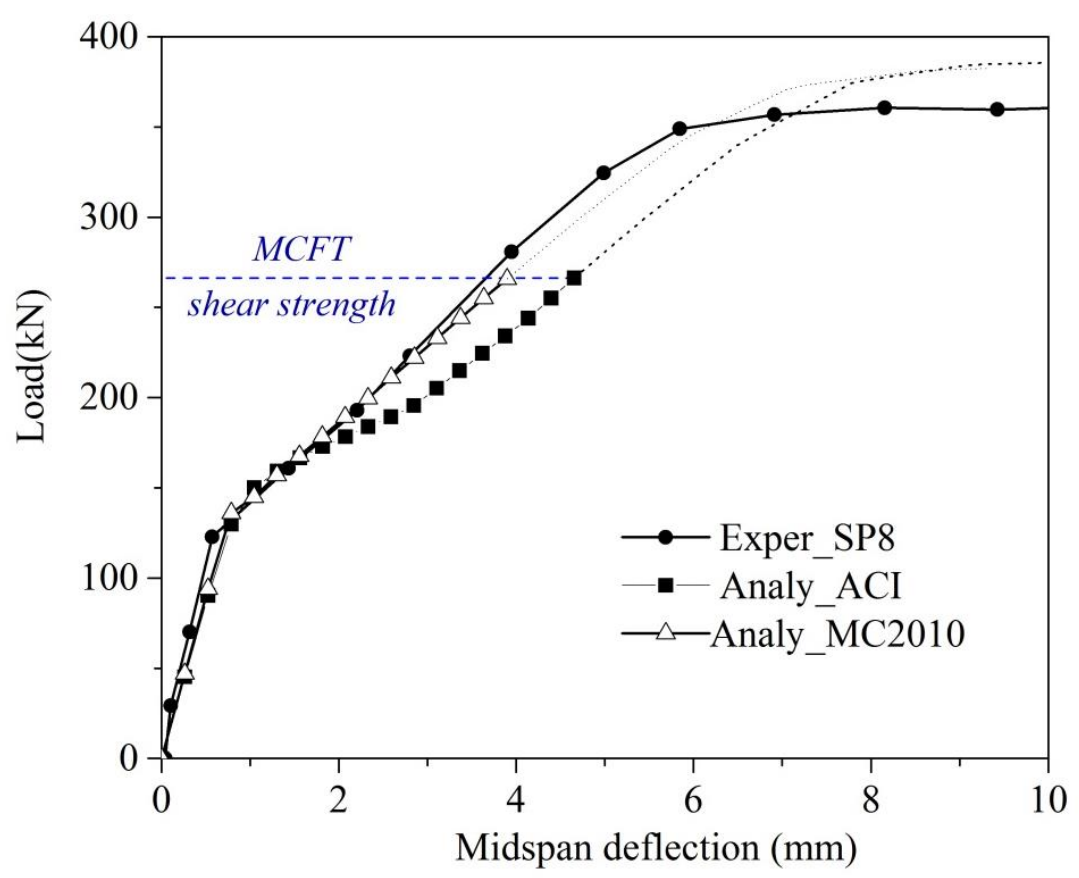

Figure 19: Analytical prediction of total load-deflection relationships of SP8 beam

714

715 